Supporting Information

\title{
Zwitterionic Covalent Organic Frameworks: Attractive Porous Host for Gas Separation and Anhydrous Proton Conduction
}

Yu Fu, Yue Wu, Shuhui Chen, Wenxiang Zhang, Ying Zhang, Tong Yan, Bolun Yang and Heping $M a^{*}$

School of Chemical Engineering and Technology, Xi'an Jiaotong University, Xi'an 710049, P. R. China. 


\section{Content}

\begin{tabular}{|c|c|}
\hline & Page No \\
\hline Experimental section & S3-S5 \\
\hline FT-IR Spectra & S6 \\
\hline${ }^{13} \mathrm{C}$ NMR spectra & S7 \\
\hline Thermo Gravimetric Analysis & S7 \\
\hline SEM and large area-EDS mapping & S8-S10 \\
\hline TEM and micro-EDS mapping & S11-S13 \\
\hline X-ray Photoelectron Spectroscopy Analyses & S14 \\
\hline Elemental Analysis & S15 \\
\hline Dye adsorption experiment & S16-S17 \\
\hline Structural optimization comparison & S17-S25 \\
\hline Chemical stability analysis of COFs & S26 \\
\hline $\mathrm{SO}_{2} / \mathrm{CO}_{2}$ separation performance & S27-S32 \\
\hline COFs as host for anhydrous proton conduction & S33-S46 \\
\hline References & S46-S49 \\
\hline
\end{tabular}




\section{Experimental Section}

\subsection{Materials}

2,4,6-triformylphloroglucinol (TP) was synthesized from Phloroglucinol according to the literature. All other solvents, reagents and chemicals were purchased from commercial suppliers without further purification.

\subsection{Experiment}

Synthesis of XJCOF-1: In a typical solvothermal methods, ethidium

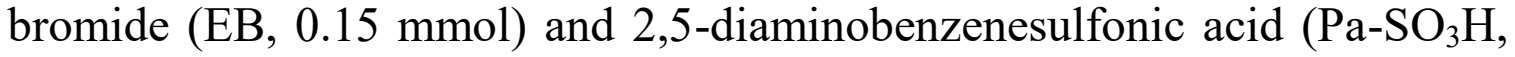
$0.15 \mathrm{mmol}$ ), along with $3 \mathrm{ml}$ of the mixture of 1,4-dioxane and mesitylene $(\mathrm{v} / \mathrm{v}, 1: 1)$ were added to a pyrex tube. After sonicating this tube for 20 minutes to fully mix the two amine monomers, this tube was charged with 1,3,5triformylphloroglucinol (Tp, $0.2 \mathrm{mmol}$ ) and $0.6 \mathrm{ml}$ of $6 \mathrm{M}$ aqueous acetic acid. After sonication for $10 \mathrm{~min}$, the tube with reaction mixture was then flash frozen at $77 \mathrm{~K}$ and degassed by three freeze-pump-thaw cycles. The tube was sealed and then heated at $120{ }^{\circ} \mathrm{C}$ for 5 days. After cooling process, a dark red precipitate was collected by filtration and washed with DMF and water for several times, followed by a Soxhlet extracting with ethanol and methanol to solvent exchange, and dried at $120{ }^{\circ} \mathrm{C}$ under vacuum overnight to get corresponding XJCOF-1 in $\sim 80 \%$ isolated yield.

Synthesis of XJCOF-2: The same synthesis procedure was followed for the synthesis of XJCOF-2 except for this COF we had taken 4,4'diaminobiphenyl-2,2'-disulfonic acid (BDSA, $0.1 \mathrm{mmol}$ ) and ethidium bromide (EB, $0.2 \mathrm{mmol}$ ). The solvent system is $3 \mathrm{ml}$ of the mixture of 1,4dioxane and mesitylene (v/v, 1:1) with $0.6 \mathrm{ml}$ of $12 \mathrm{M}$ acetic acid. Other same 
monomers and synthetic procedure as like XJCOF-1 was followed to give $\sim 82 \%$ isolate yield.

Synthesis of XJCOF-3: In case of XJCOF-3, we have taken 4,4'-diamino2,2'-stilbenedisulfonic acid (DASD, $0.1 \mathrm{mmol}$ ) and $3 \mathrm{~mL}(1: 1)$ solvent mixture of Dimethylacetamide and 1,2-dichlorobenzene with $0.6 \mathrm{ml}$ of $12 \mathrm{M}$ acetic acid. Other same monomers and synthetic procedure as like XJCOF-2 was followed to give $\sim 80 \%$ isolate yield.

Triazole/imidazole loading inside XJCOFs: Sampled $120 \mathrm{mg}$ COFs (activated for 1 day at $120^{\circ} \mathrm{C}$ under vacuum), and added them to tube, the bottom of where was covered with triazole. After vacuuming, triazole was vaporized into the $\mathrm{COF}$ at $150{ }^{\circ} \mathrm{C}$ overnight to yield trz@XJCOFs (trz@XJCOF=XJCOF doped triazole). The same synthesis procedure was followed for the synthesis of im@XJCOFs (im@XJCOF=XJCOF doped imidazole) except for these COFs we replaced triazole with imidazole and the temperature turns into $120^{\circ} \mathrm{C}$.

\subsection{Analytical characterization}

Fourier transform infrared spectra (FT-IR) were measured using Nicolet iS50 attenuated total reflectance IR spectrometer. ${ }^{13} \mathrm{C}$ MAS solid state nuclear magnetic resonance (NMR) spectrum was taken in a Bruker 400M NMR spectrometer. Powder X-Ray Diffraction (PXRD) data were recorded by Bruker D8 Advance instrument with $\mathrm{Cu}-\mathrm{K}$ a radiation operating at $50 \mathrm{kV}$ and a current of $200 \mathrm{~mA}$. X-ray photoelectron spectroscopy (XPS) analysis were performed using Thermo Fisher ESCALAB Xi+ analyzer. Elemental analysis was tested via Vario EL Cube organic elemental analyzer. Scanning Electron Microscopy (SEM) images were collected using MAIA3LMH microscope 
with Aztec X-maxN $50 \mathrm{~mm}^{2}$ detector for EDX analyze. Nitrogen adsorption/desorption isotherm at $77 \mathrm{k}$ were obtained by Micromeritics ASAP 2460 analyzer. Thermo gravimetric analyses (TGA) were carried out on a STA449F5 analyzer under air atmosphere within a temperature range of 30$800{ }^{\circ} \mathrm{C}$. Zeta potential was measured using Zerasizer nano ZSE in the conductivity range of $0-200 \mathrm{mS} / \mathrm{cm}$. Transmission Electron Microscope (TEM) was collected using JEOL JEM-F200 (HR) with HAADF annex. Impedance spectroscopy and Dielectric properties were measured using Novocontrol Concept 80 broadband dielectric spectrometer in the frequency range of $10^{-1} \mathrm{~Hz}-10 \mathrm{MHz}$. $\mathrm{SO}_{2}$ adsorption isotherms are obtained by surface area and porosity analyzer (BSD-PS1). Prior to the physisorption measurement, the sample was dehydrated at $120{ }^{\circ} \mathrm{C}$ for $12 \mathrm{~h}$ under high vacuum $\left(<10^{-6}\right.$ bar $)$. 
(a)

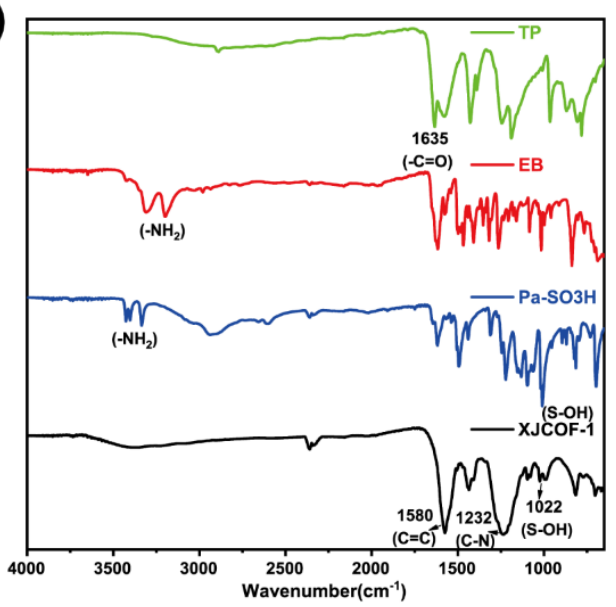

(b)

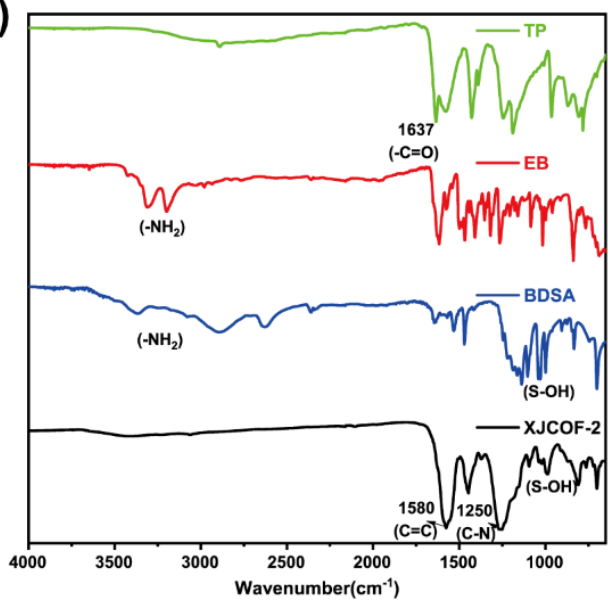

(c)

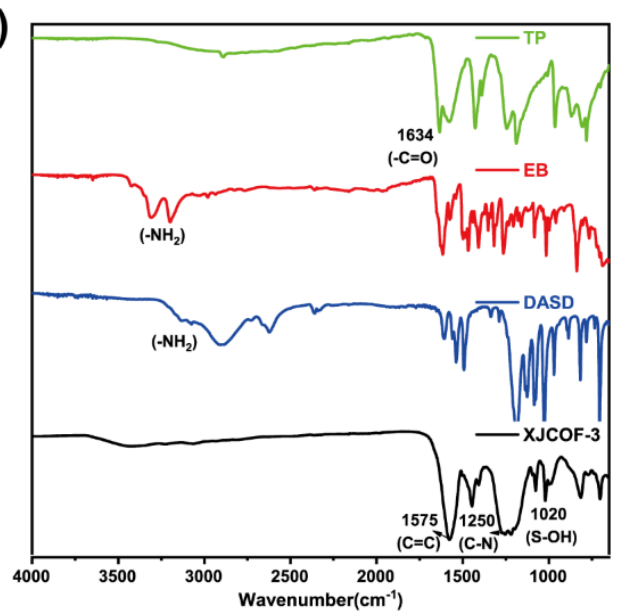

Figure S1. Fourier transform infrared spectra (FT-IR) of the COFs compared with reactants XJCOF-1 (a), XJCOF-2 (b) and XJCOF-3 (c). 

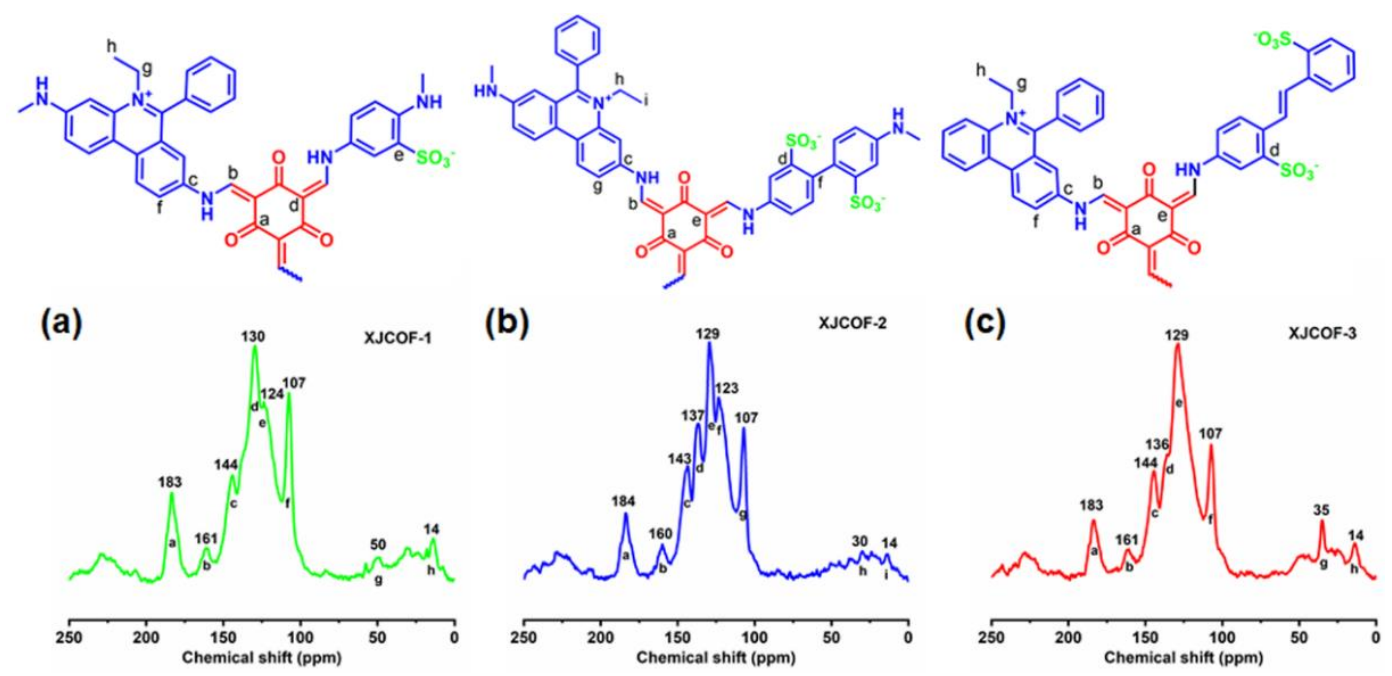

Figure S2. 13C CP-MAS NMR spectra of XJCOF-1, XJCOF-2 and XJCOF-

3. Corresponding chemical structures are shown above the pictures.

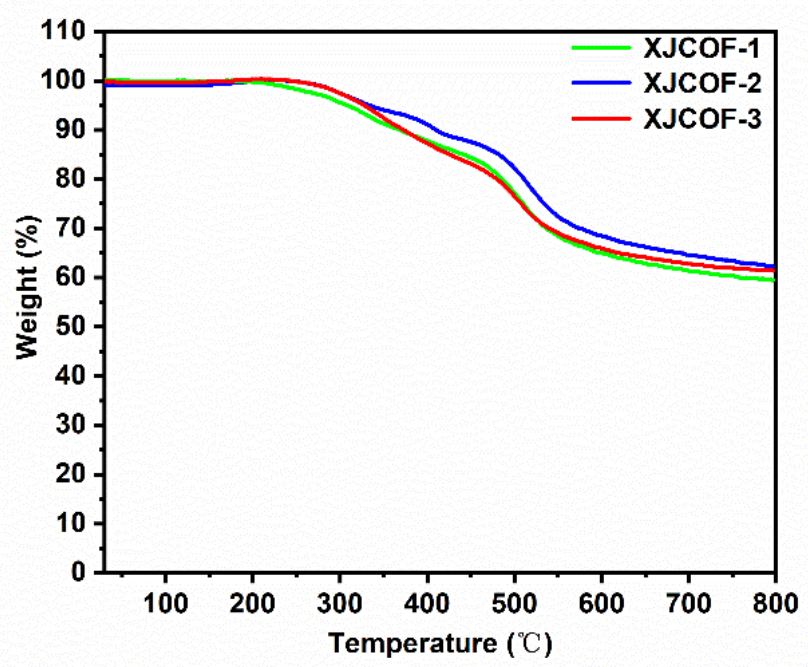

Figure S3. TG curves of the activated XJCOFs. The first weight loss stage is due to the disintegration of sulfonic acid groups and the second one is due to the decomposition of COF backbones. 

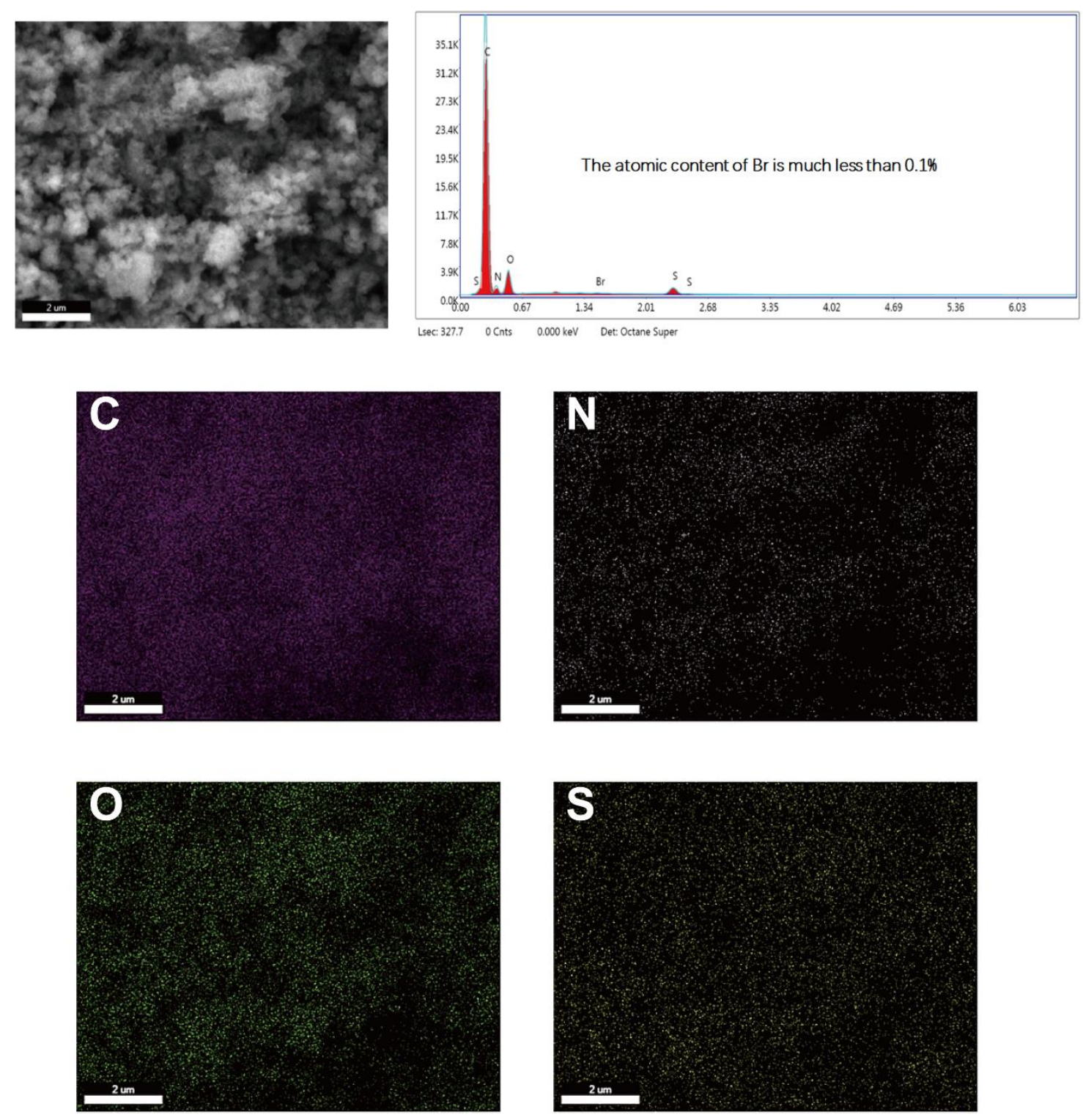

Figure S4. EDS mapping and elemental content analysis from SEM-related EDS in XJCOF-1. 

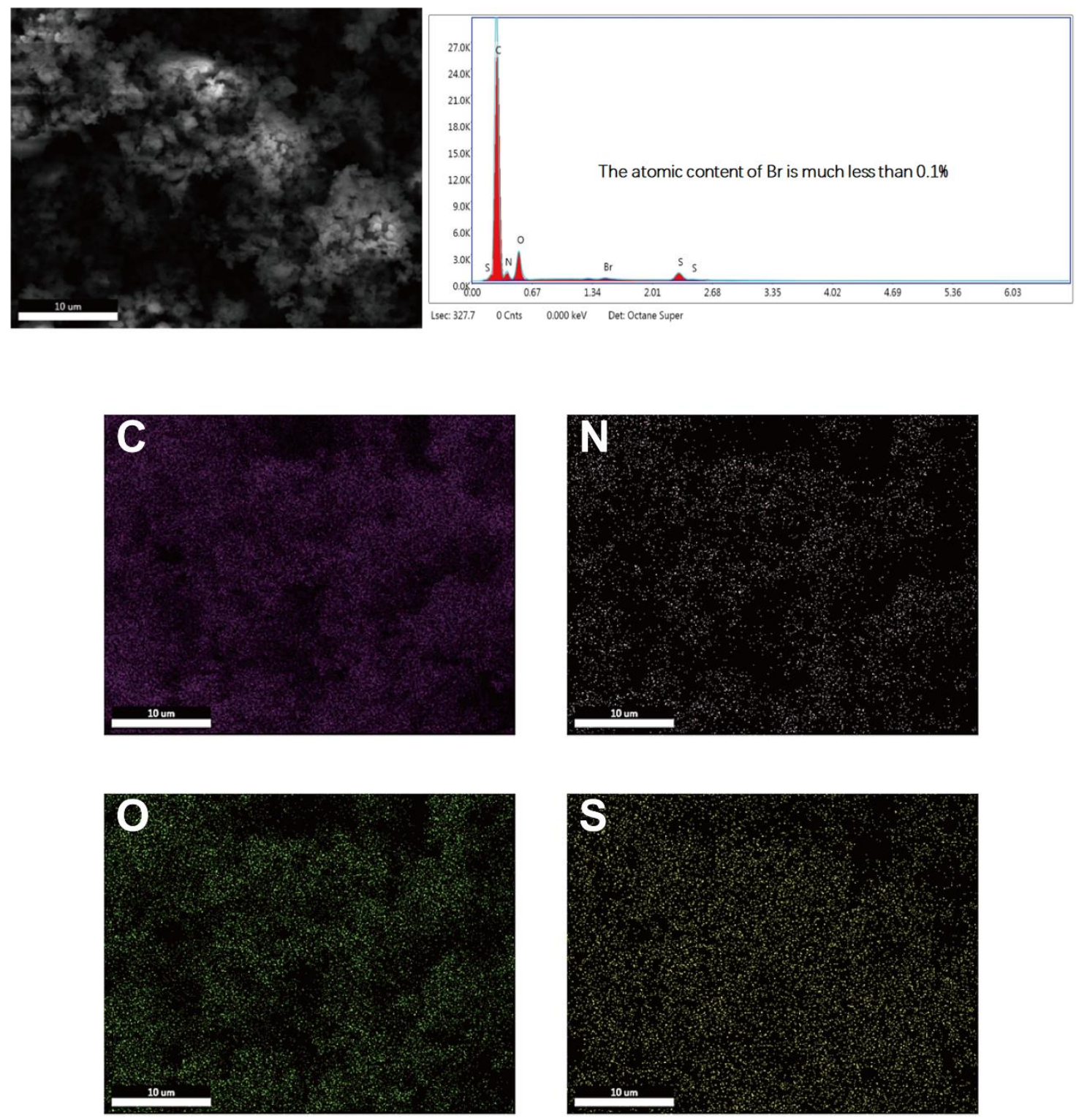

Figure S5. EDS mapping and elemental content analysis from SEM-related EDS in XJCOF-2. 

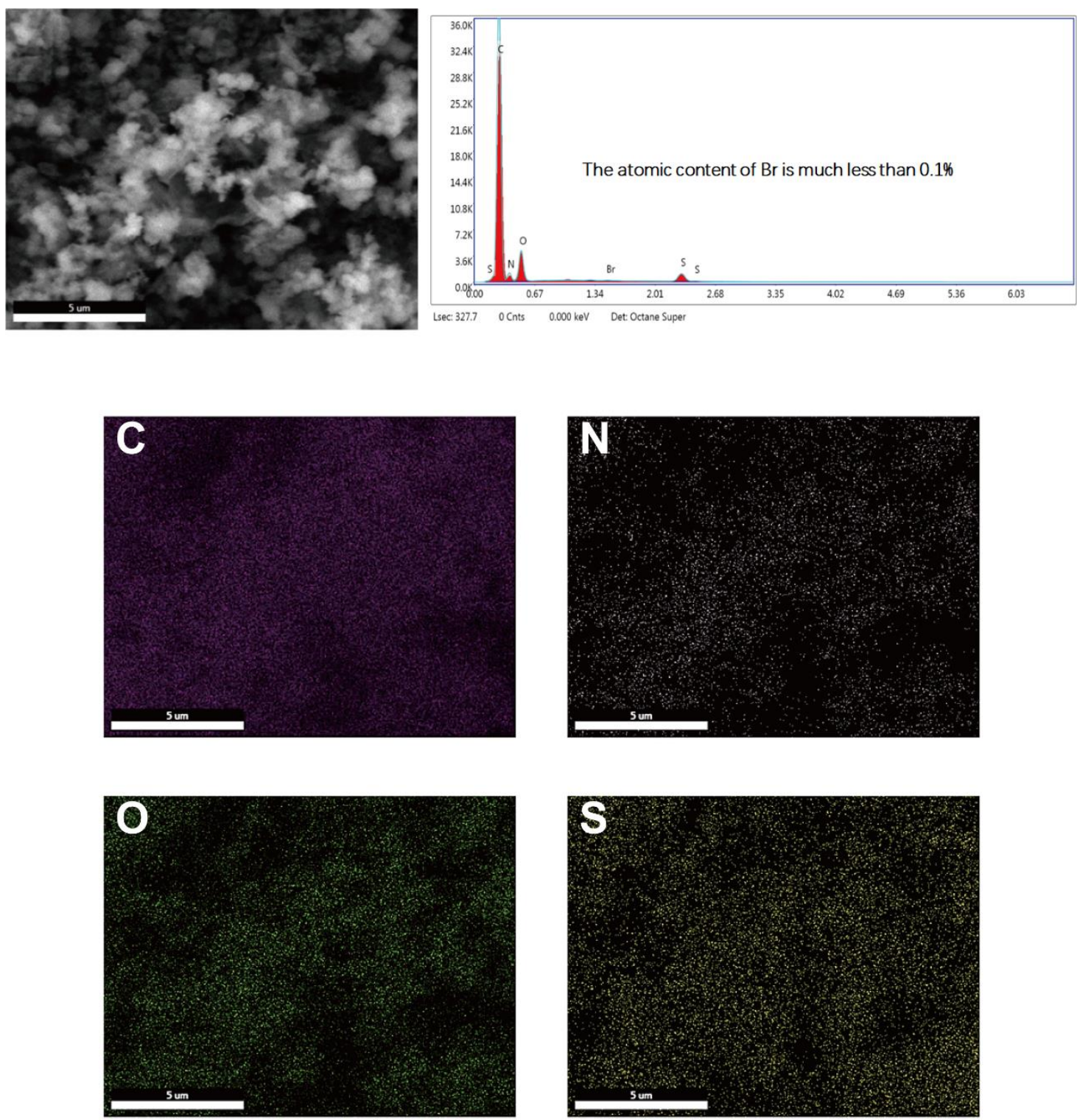

Figure S6. EDS mapping and elemental content analysis from SEM-related EDS in XJCOF-3. 

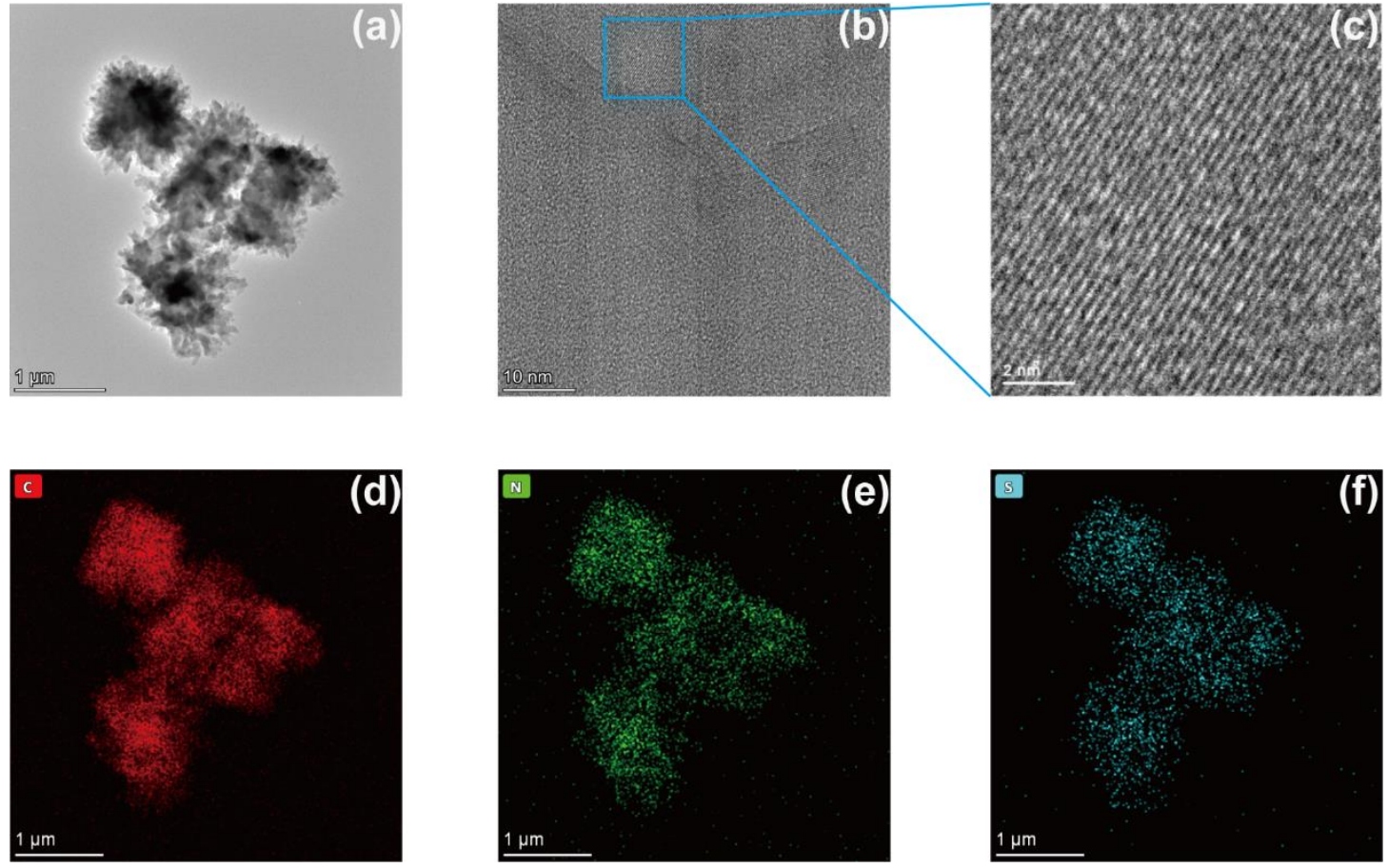

Figure S7. (a) TEM images of XJCOF-2, (b) HR-TEM image of XJCOF-2 and its partial enlarged detail (c). The TEM-related EDS mapping of element $\mathrm{C}(\mathrm{d}), \mathrm{N}(\mathrm{e})$ and $\mathrm{S}(\mathrm{f})$ in XJCOF-2. 

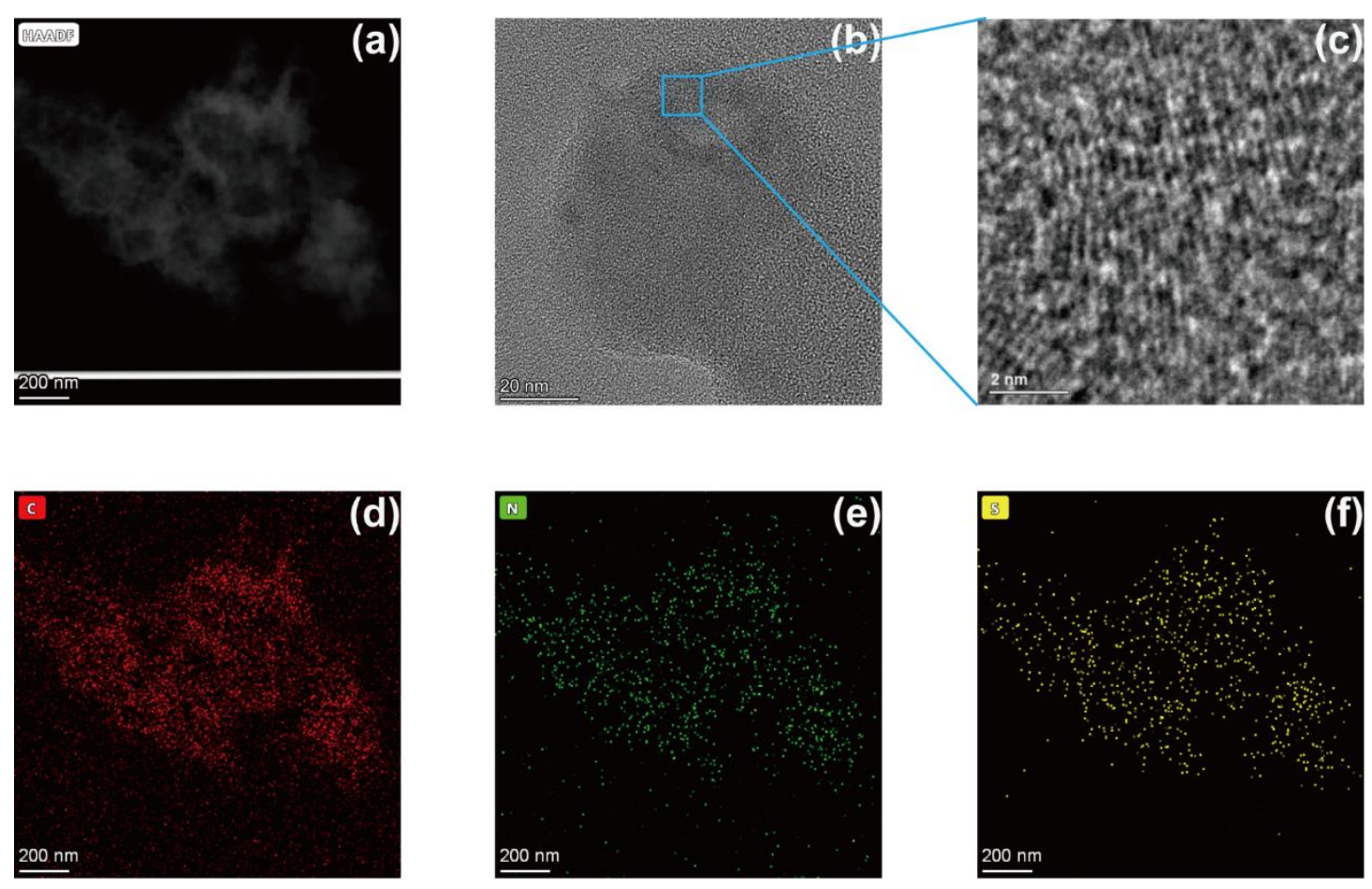

Figure S8. (a) TEM images of XJCOF-3, (b) HR-TEM image of XJCOF-3 and its partial enlarged detail (c). The TEM-related EDS mapping of element $\mathrm{C}(\mathrm{d}), \mathrm{N}(\mathrm{e})$ and $\mathrm{S}(\mathrm{f})$ in XJCOF-3. 
Physical mixture of sulfonate COF and EB-COF
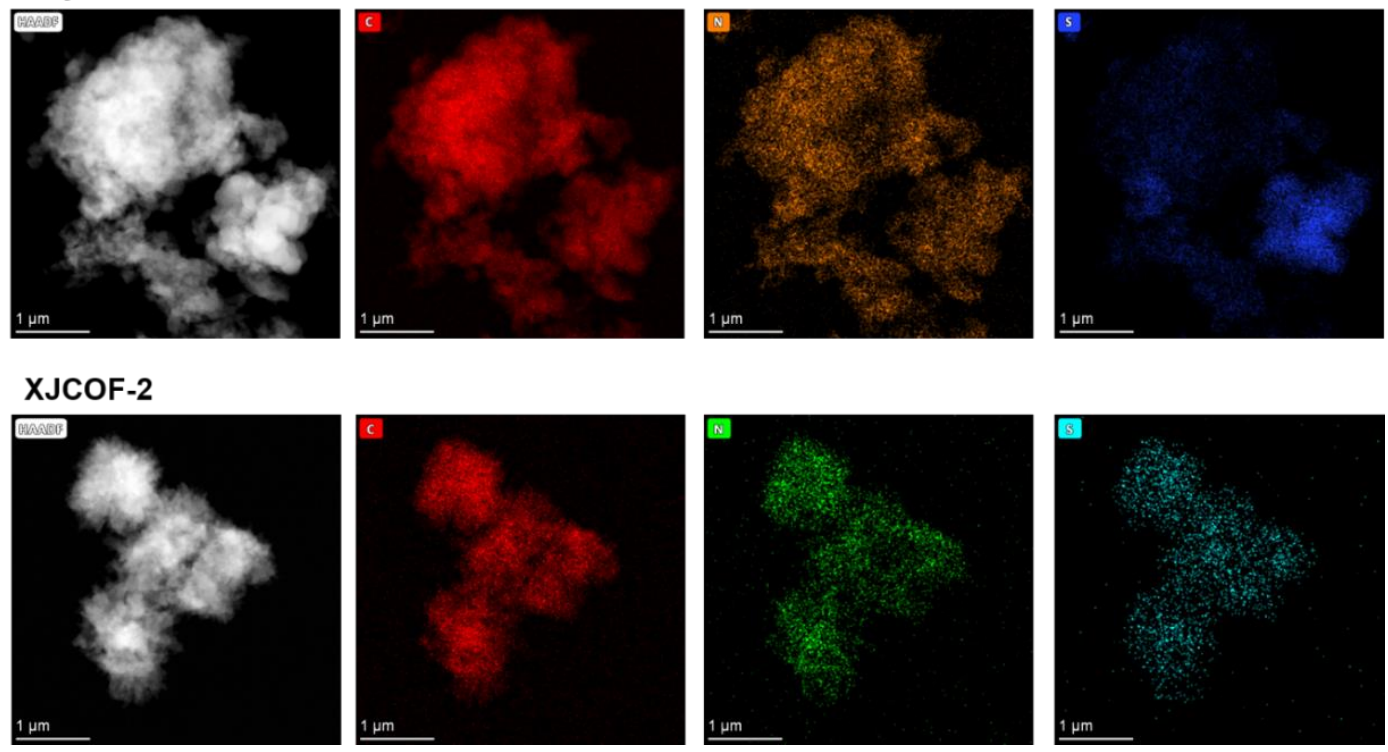

Figure S9. The TEM micro-EDS mapping comparison between the XJCOF-

2 and the physical mixture of corresponding sulfonate COF and EB-COF.

Physical mixture of sulfonate COF and EB-COF
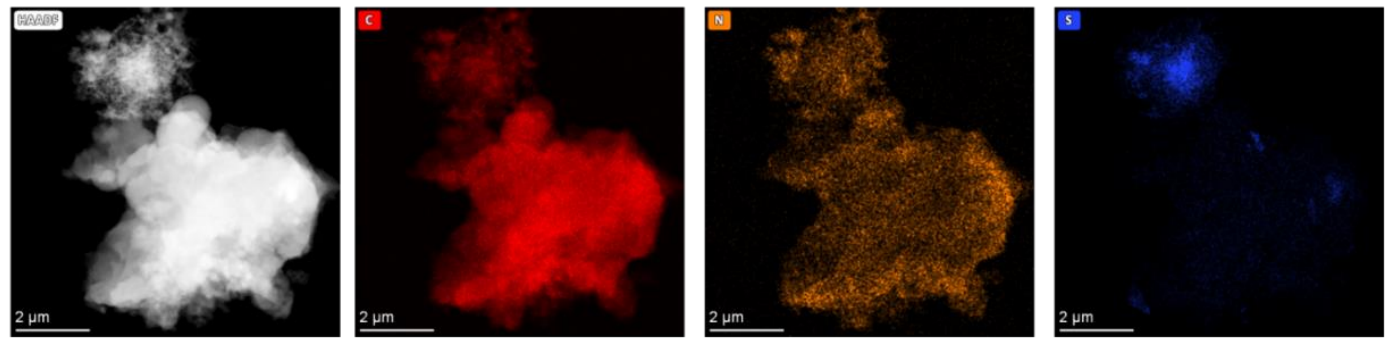

\section{XJCOF-3}
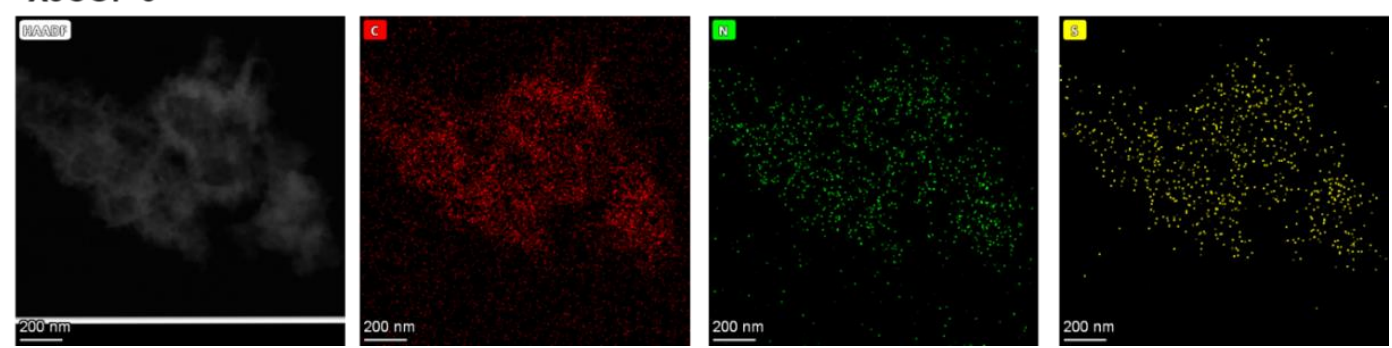

Figure S10. The TEM micro-EDS mapping comparison between the XJCOF-

3 and the physical mixture of corresponding sulfonate COF and EB-COF. 
(a)

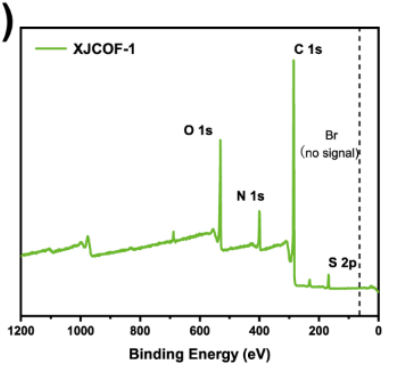

(d)

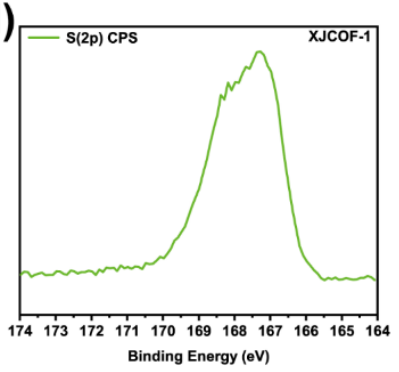

(b)

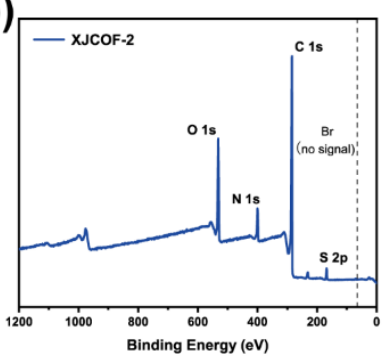

(e)

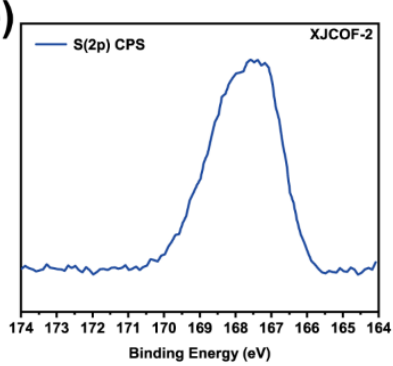

(c)

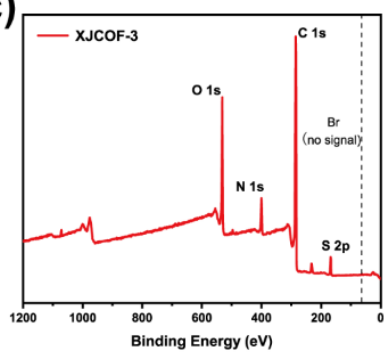

(f)

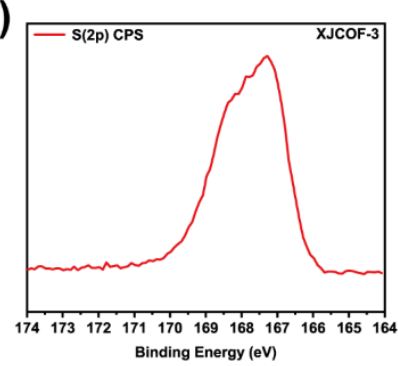

Figure S11. (a)-(c) XPS spectra of XJCOF-1, XJCOF-2 and XJCOF-3; S 2p XPS of XJCOF-1(d), XJCOF-2(e) and XJCOF-3(f).

\begin{tabular}{|c|c|c|c|}
\hline & XJCOF-1 & XJCOF-2 & XJCOF-3 \\
\hline N/S ratio & 4.5 & 3.5 & 3.3 \\
\hline Theoretical ratio & 5 & 4 & 4 \\
\hline
\end{tabular}

Table S1. The N/S ratio (atomic ratio) calculated from XPS. 


\begin{tabular}{|c|c|c|c|c|c|}
\hline & N (\%) & C (\%) & H (\%) & S (\%) & C/N Ratio \\
\hline XJCOF-1 & 9.46 & 63 & 4.733 & 3.686 & 6.66 \\
\hline $\begin{array}{c}\text { Theoretical } \\
\text { value }\end{array}$ & 9.396 & 62.82 & 4.16 & 4.29 & 6.69 \\
\hline
\end{tabular}

Table S2. The C, H, N and S elemental analysis of XJCOF-1 (Mass ratio).

\begin{tabular}{|l|l|l|l|l|l|}
\hline & N (\%) & C (\%) & H (\%) & S (\%) & C/N Ratio \\
\hline XJCOF-2 & 8.33 & 63.25 & 4.753 & 3.621 & 7.59 \\
\hline $\begin{array}{c}\text { Theoretical } \\
\text { value }\end{array}$ & 8.38 & 64.67 & 4.19 & 4.79 & 7.72 \\
\hline
\end{tabular}

Table S3. The C, H, N and S elemental analysis of XJCOF-2 (Mass ratio).

\begin{tabular}{|c|l|l|l|l|l|}
\hline & N (\%) & $\mathbf{C ~ ( \% )}$ & H (\%) & S (\%) & C/N Ratio \\
\hline XJCOF-3 & 8.32 & 60.58 & 4.714 & 4.217 & 7.2772 \\
\hline $\begin{array}{c}\text { Theoretical } \\
\text { value }\end{array}$ & 8.22 & 65.2 & 4.26 & 4.7 & 7.93 \\
\hline
\end{tabular}

Table S4. The C, H, N and S elemental analysis of XJCOF-3 (Mass ratio). 


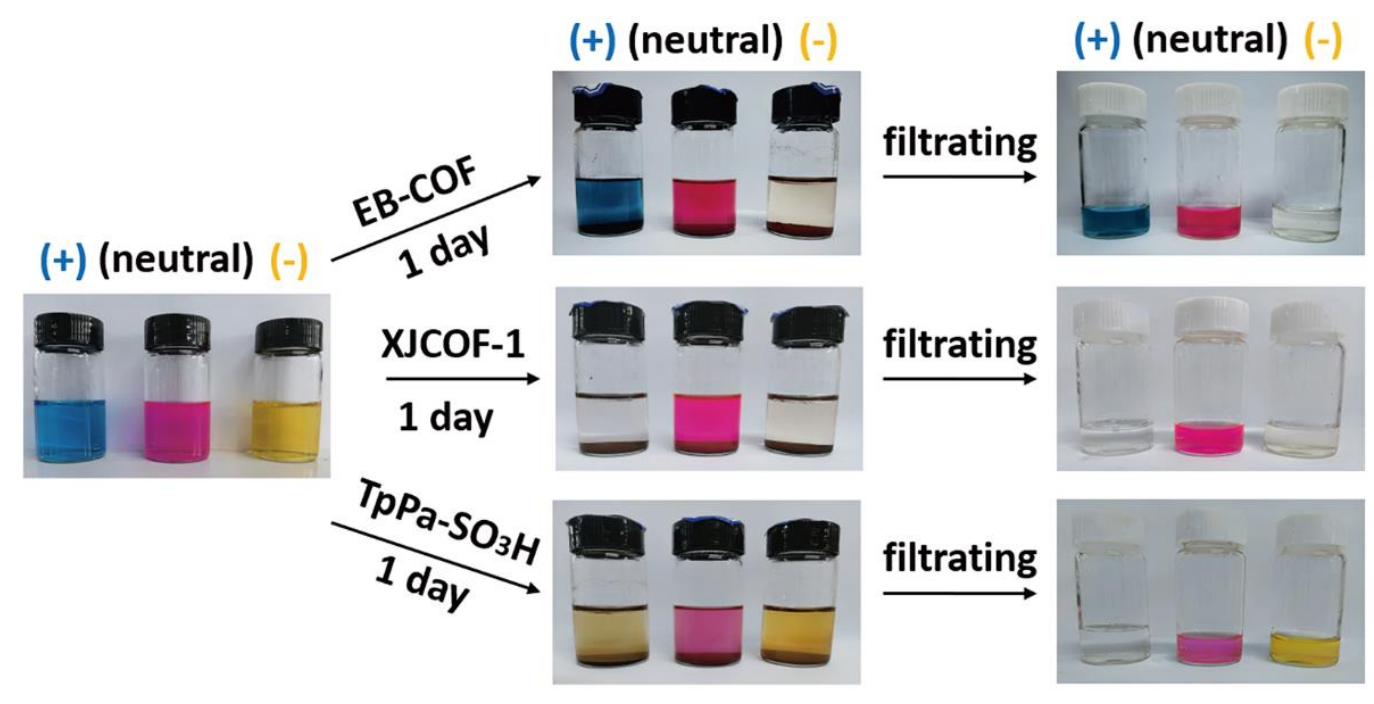

Figure S12. Dye adsorption experiment of XJCOF-1 and its corresponding anionic $\mathrm{COF}\left(\mathrm{TpPa}-\mathrm{SO}_{3} \mathrm{H}\right)$ and cationic $\mathrm{COF}(\mathrm{EB}-\mathrm{COF})$. From left to right, the dyes are methylene blue (positively charged), Nile red (neutral), and methyl orange (negatively charged), respectively. (note: the last set of pictures mean partial filtrate)

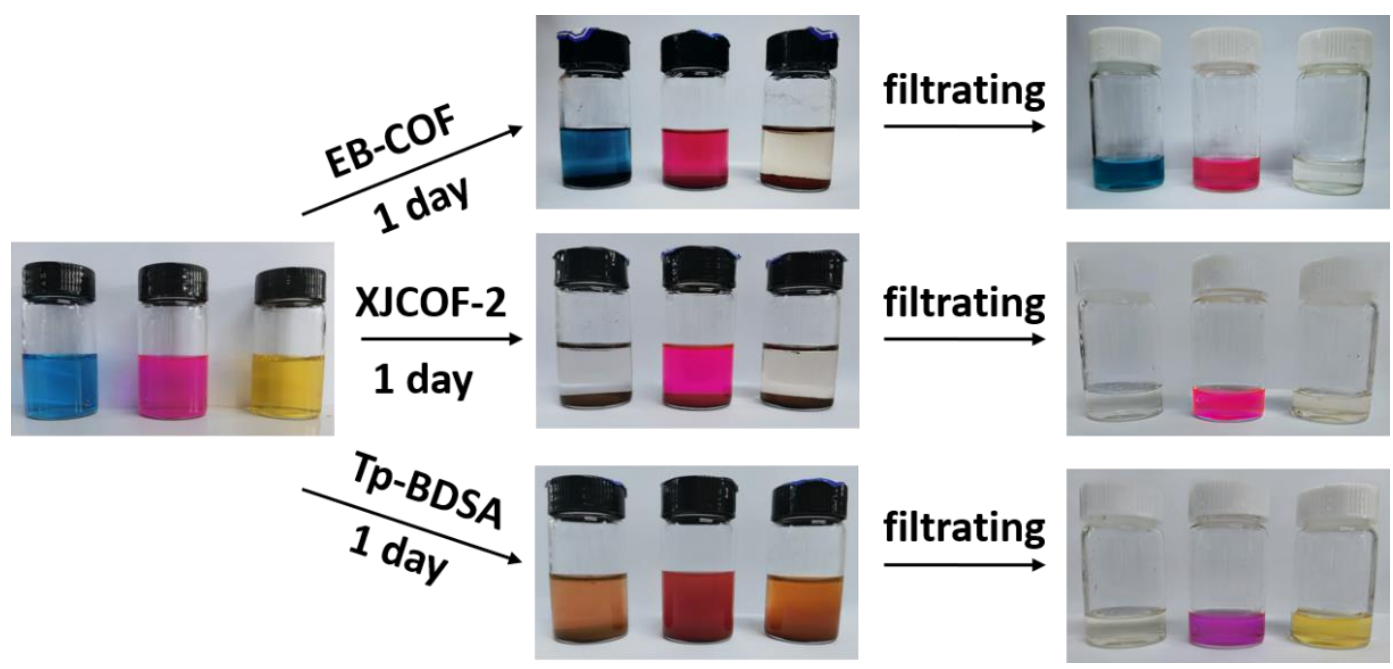

Figure S13. Separation experiment about XJCOF-2 and its corresponding anionic COF (Tp-BDSA) and cationic COF (EB-COF). 


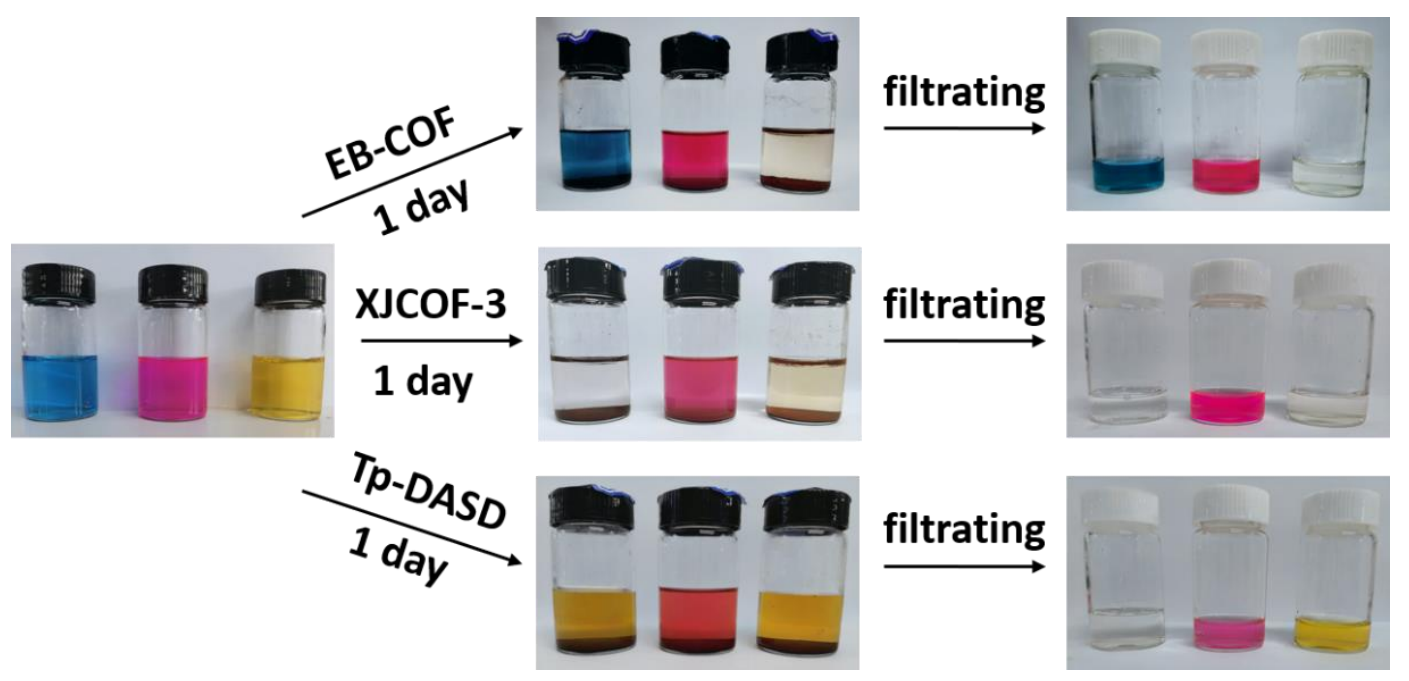

Figure S14. Separation experiment about XJCOF-3 and its corresponding anionic COF (Tp-DASD) and cationic COF (EB-COF).

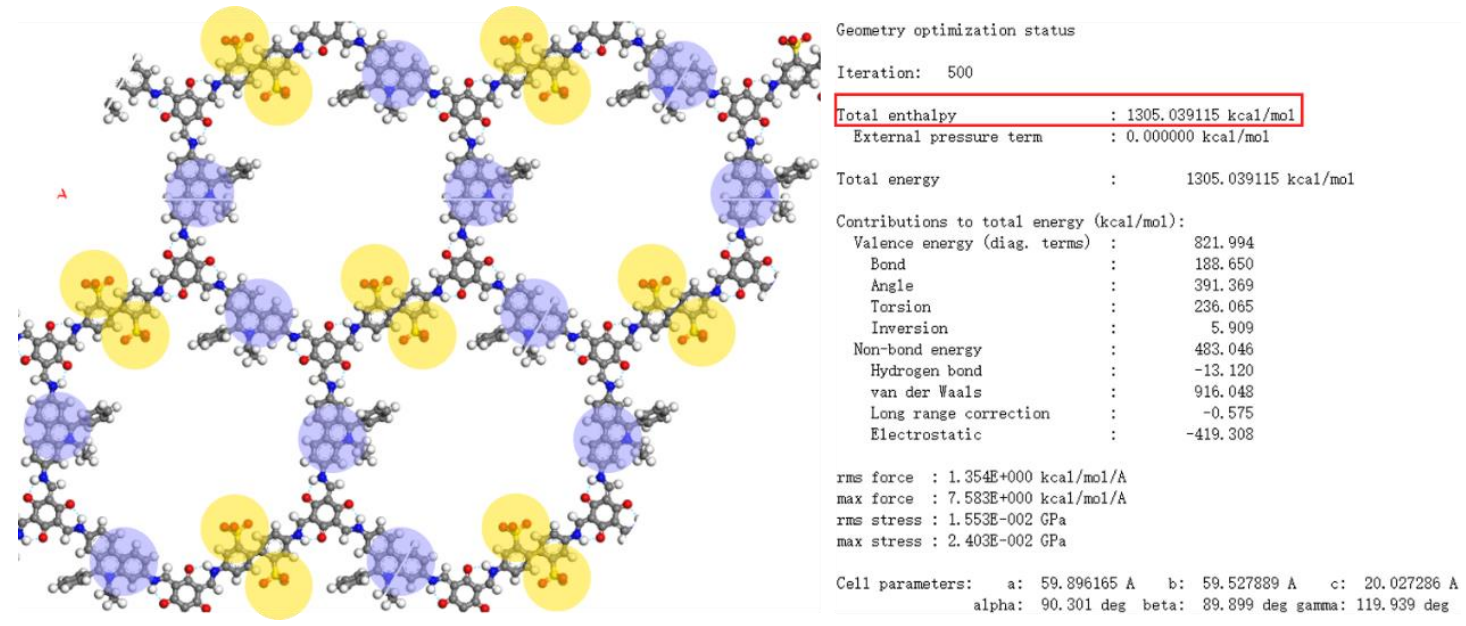

Figure S15. Schematic diagram of the XJCOF-2 structure with cross distribution of positive and negative linkers. The cationic and anionic sites are marked with blue and orange circles respectively. 

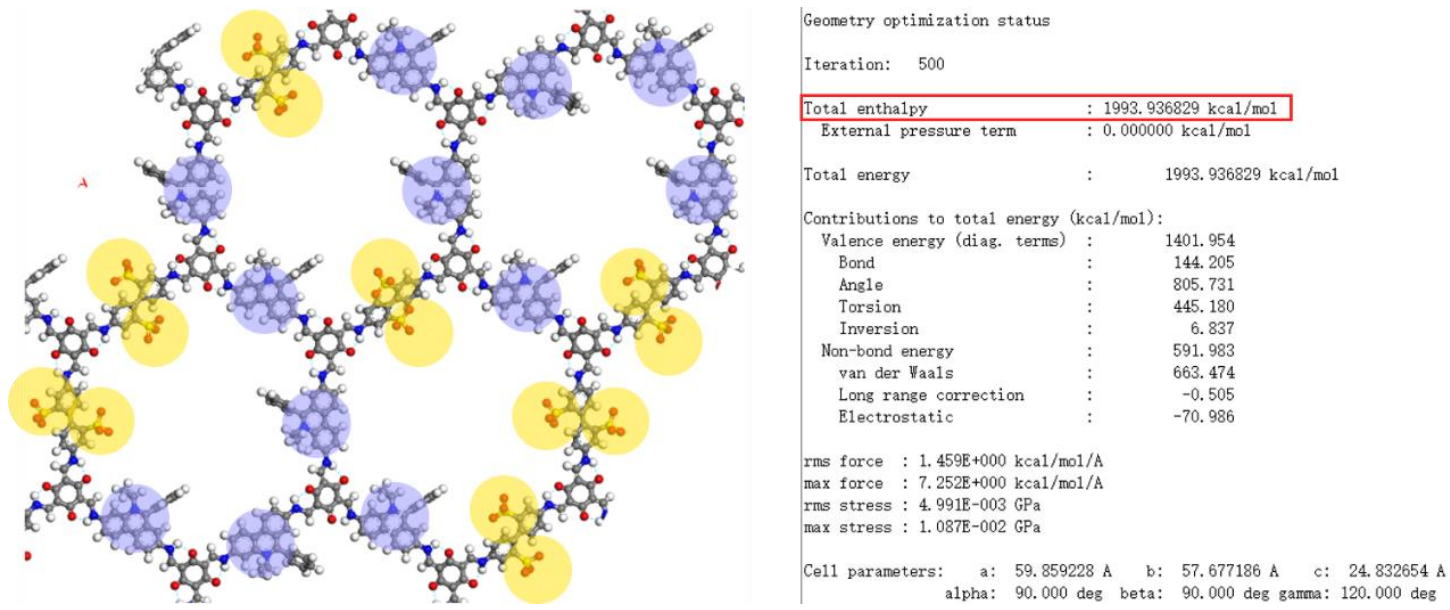

Figure S16. Schematic diagram of possible XJCOF-2 structure with random linkers-arrangement. The cationic and anionic sites are marked with blue and orange circles respectively.

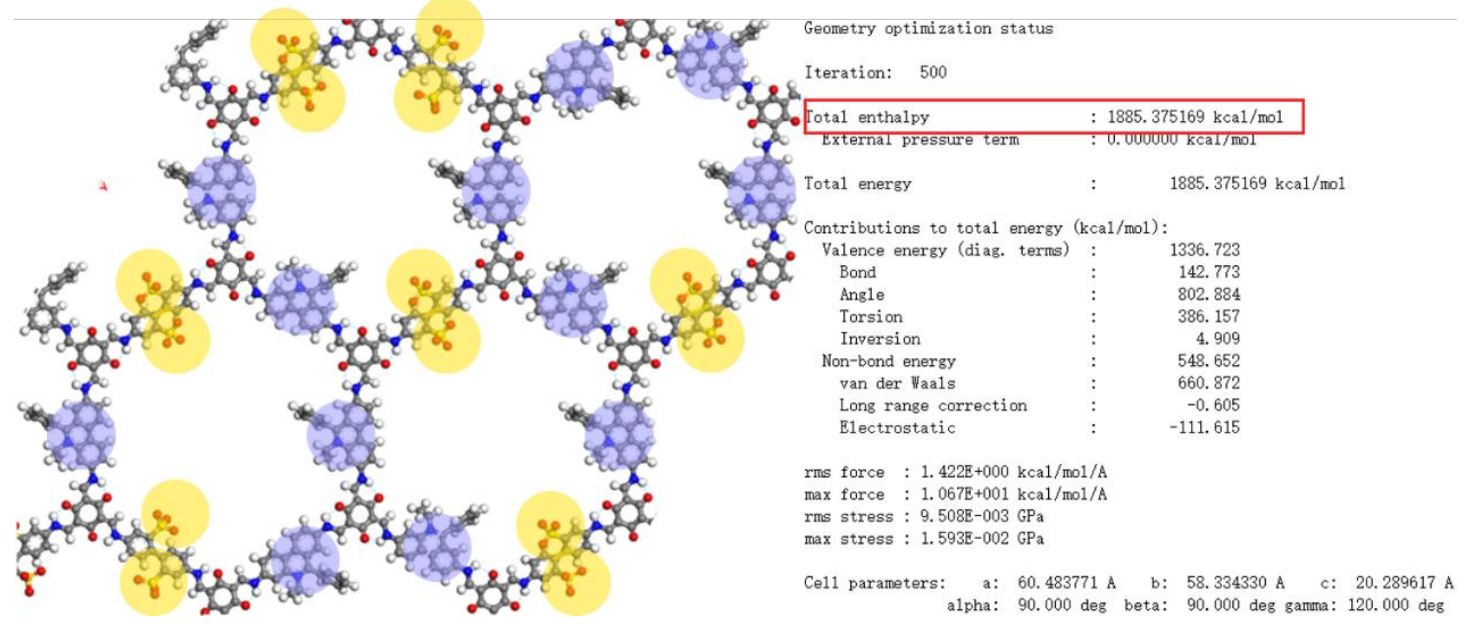

Figure S17. Schematic diagram of possible XJCOF-2 structure with random linkers-arrangement. The cationic and anionic sites are marked with blue and orange circles respectively. 


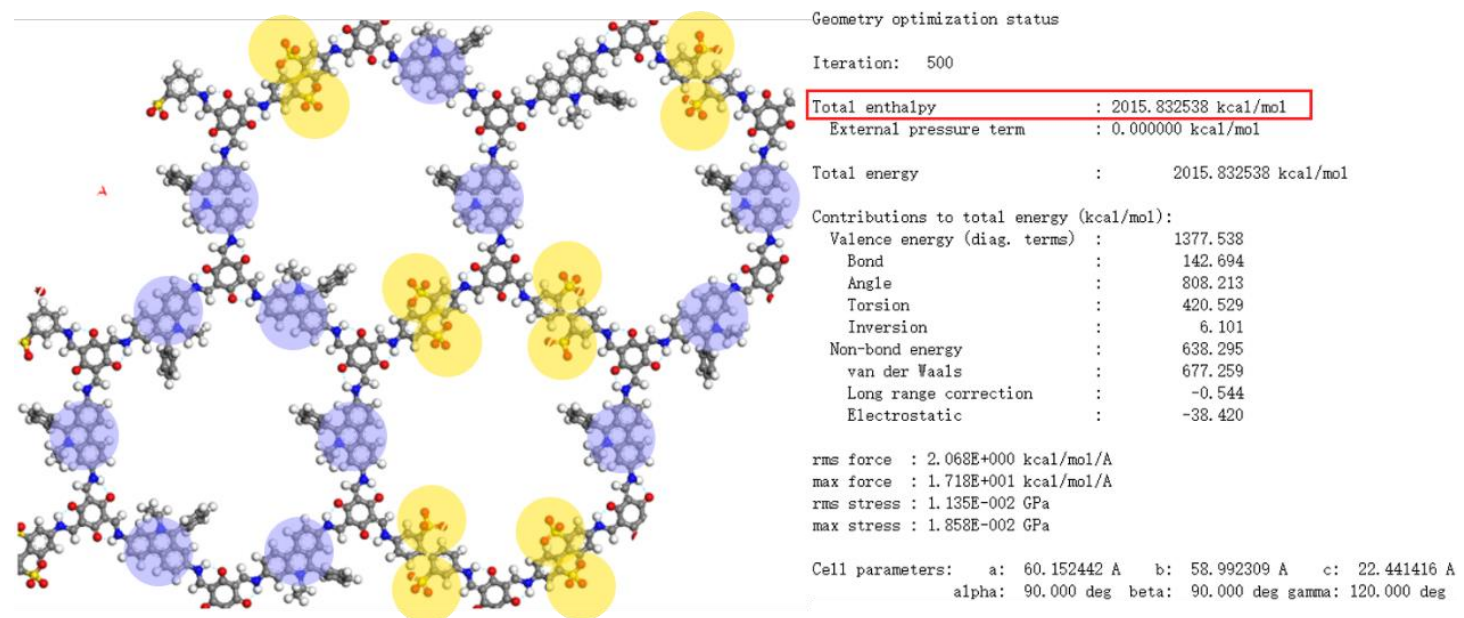

Figure S18. Schematic diagram of possible XJCOF-2 structure with random linkers-arrangement. The cationic and anionic sites are marked with blue and orange circles respectively.

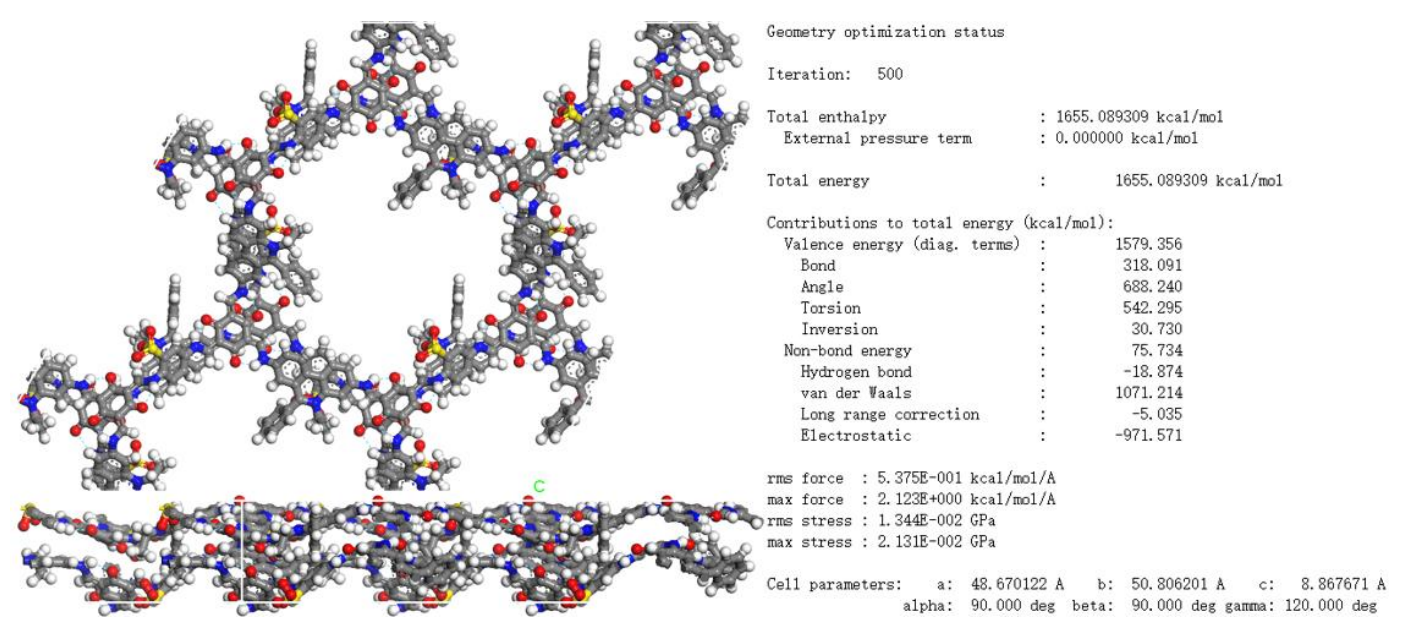

Figure S19. The new rotate-AA stacking structure diagram (top view and side view) of XJCOF-1 and the total energy after geometrical energy minimization. 


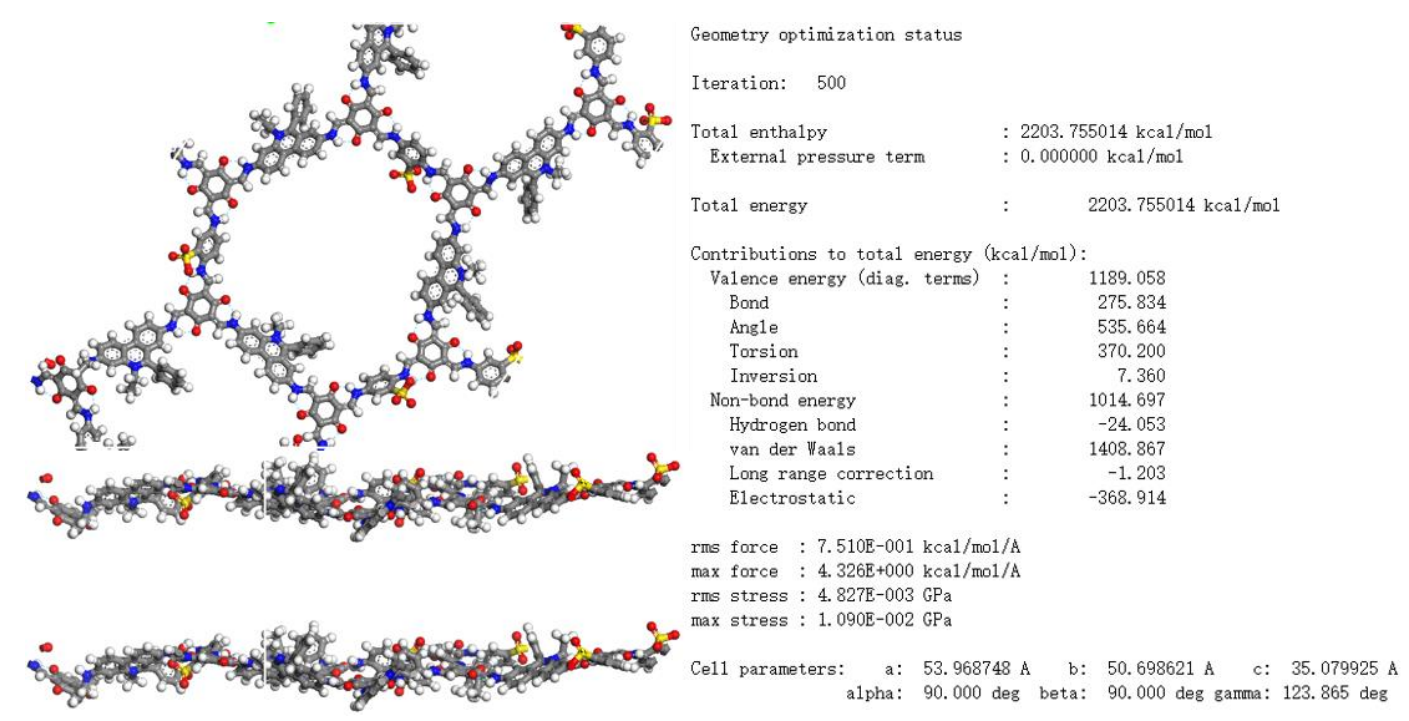

Figure S20. AA stacking structure (top view and side view) of XJCOF-1 and the total energy after geometrical energy minimization.

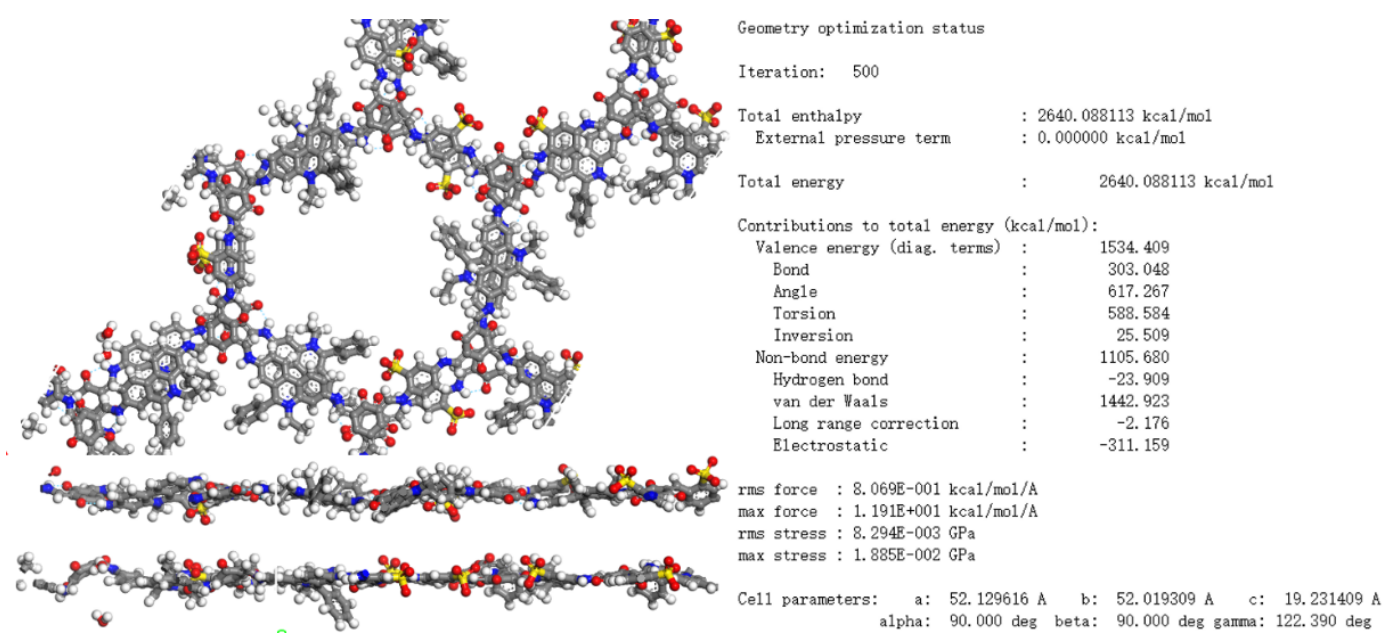

Figure S21. Offset AA stacking structure (top view and side view) of XJCOF1 and the total energy after geometrical energy minimization. 

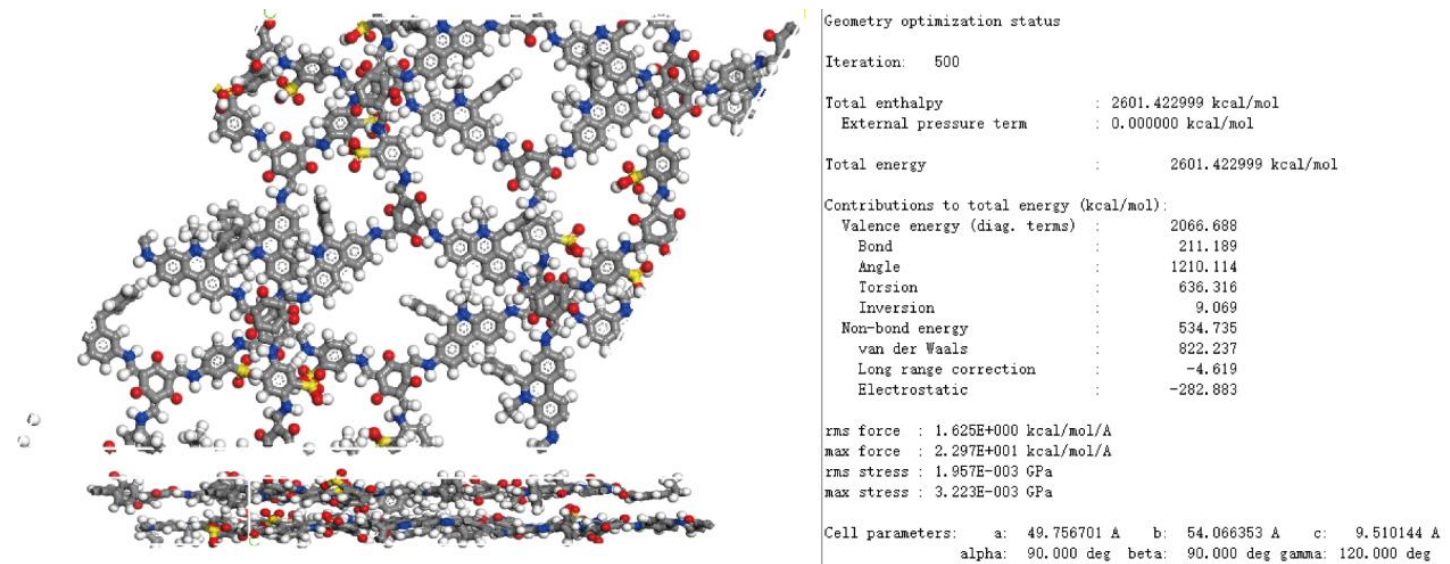

Figure S22. AB stacking structure (top view and side view) of XJCOF-1 and the total energy after geometrical energy minimization.

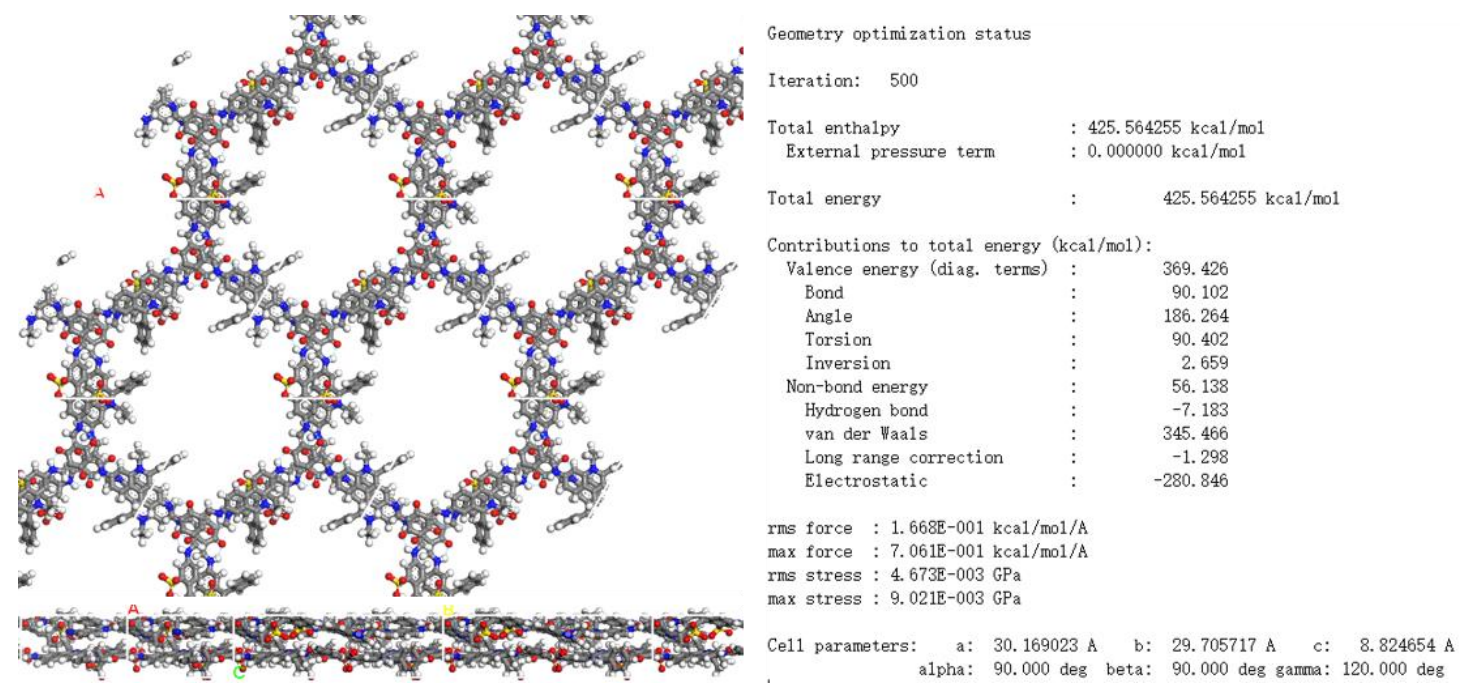

Figure S23. The new rotate-AA stacking structure diagram (top view and side view) of XJCOF-2 and the total energy after geometrical energy minimization. 


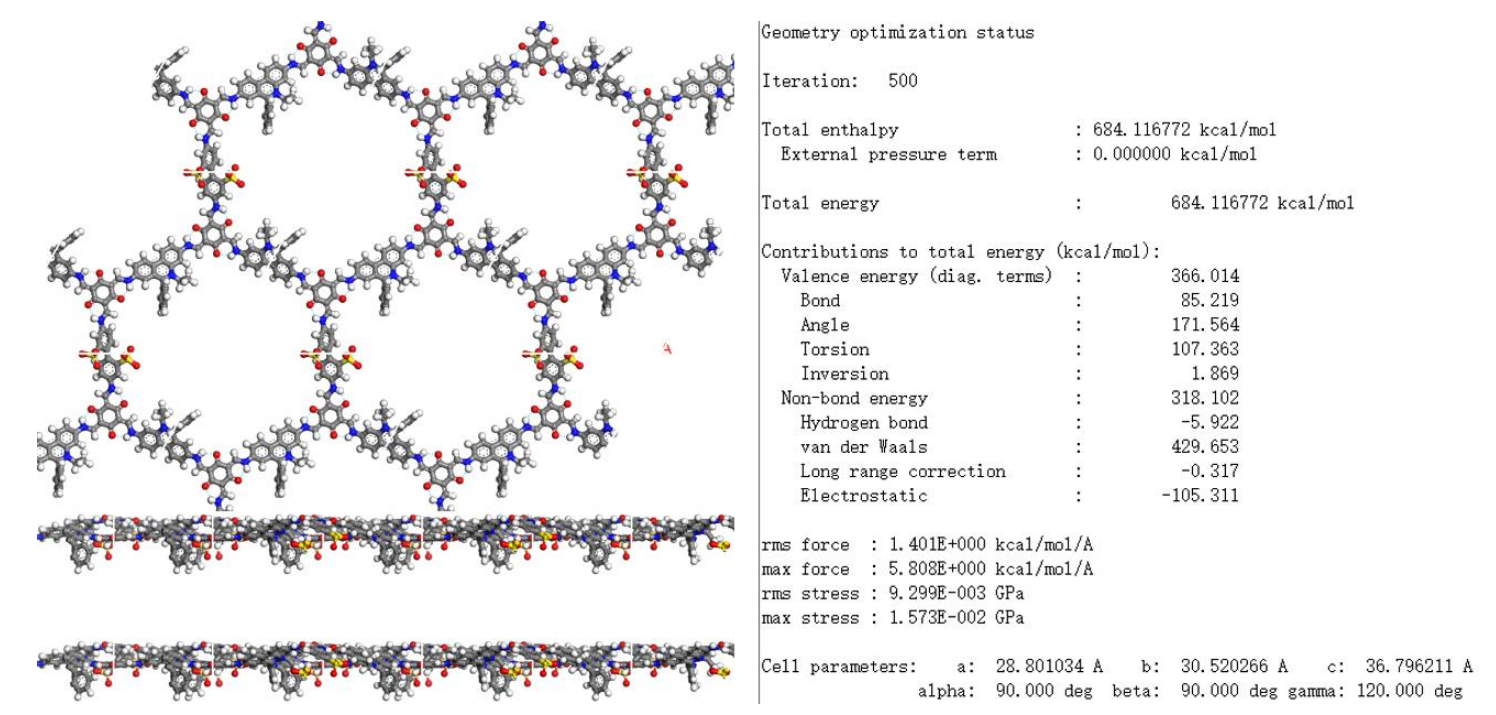

Figure S24. AA stacking structure (top view and side view) of XJCOF-2 and the total energy after geometrical energy minimization.

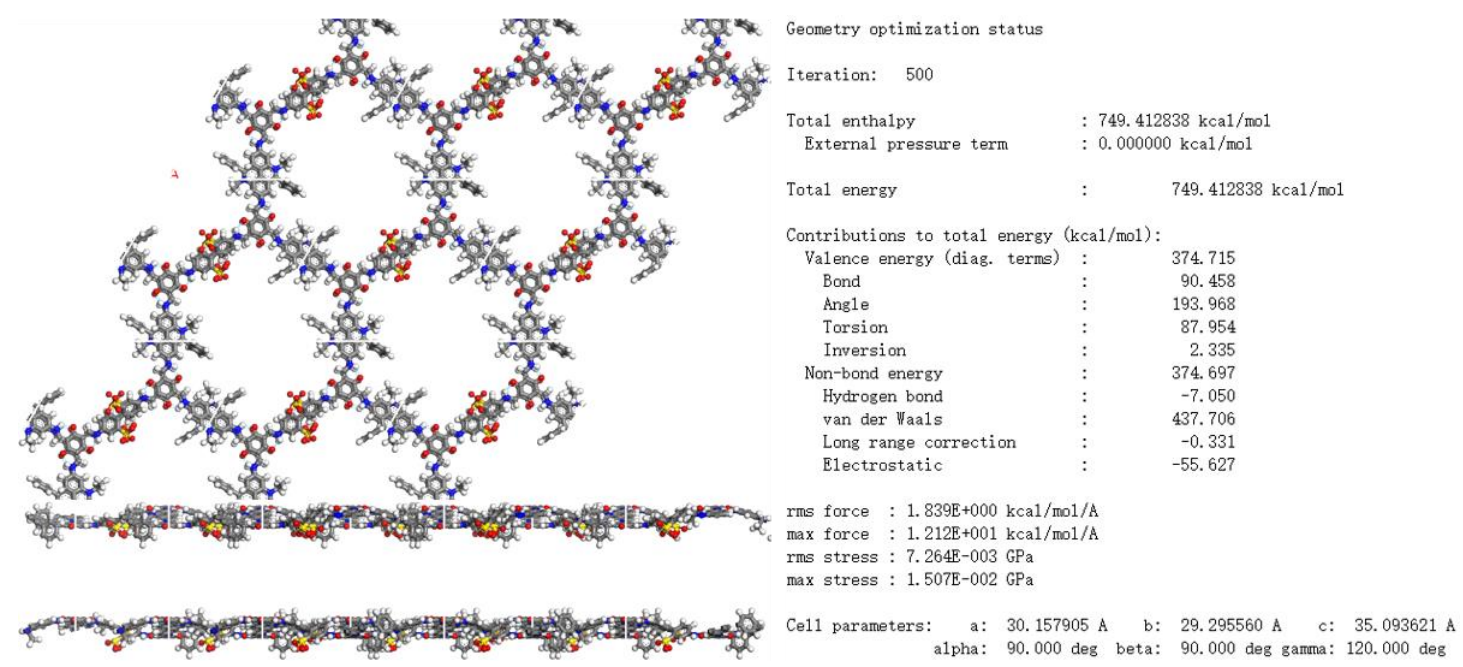

Figure S25. Offset AA stacking structure (top view and side view) of XJCOF-

2 and the total energy after geometrical energy minimization. 


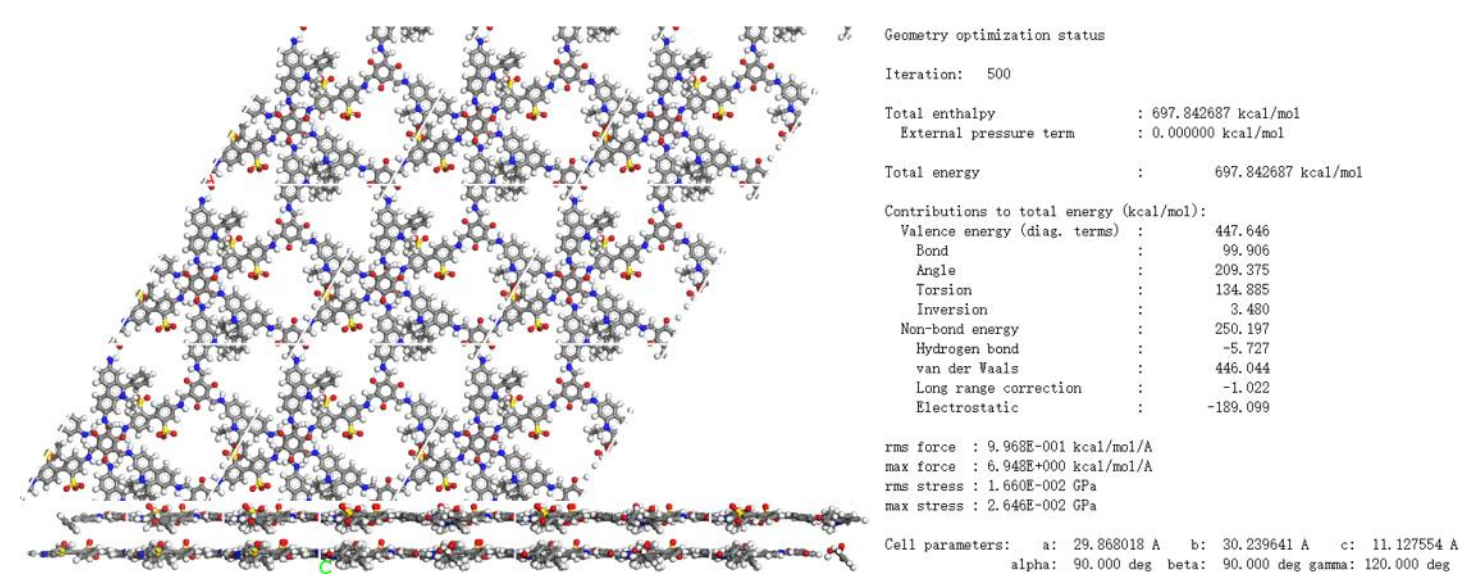

Figure S26. AB stacking structure (top view and side view) of XJCOF-2 and the total energy after geometrical energy minimization.

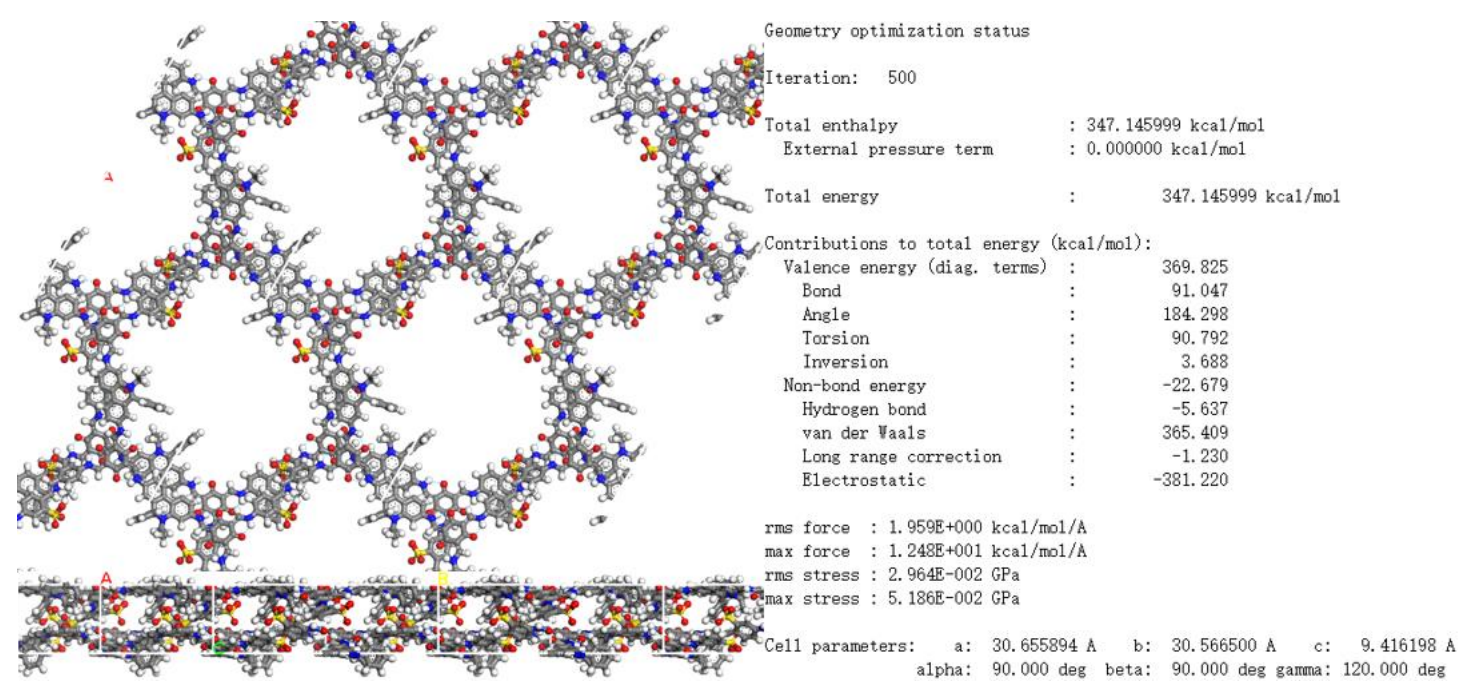

Figure S27. The new rotate-AA stacking structure diagram (top view and side view) of XJCOF-3 and the total energy after geometrical energy minimization. 


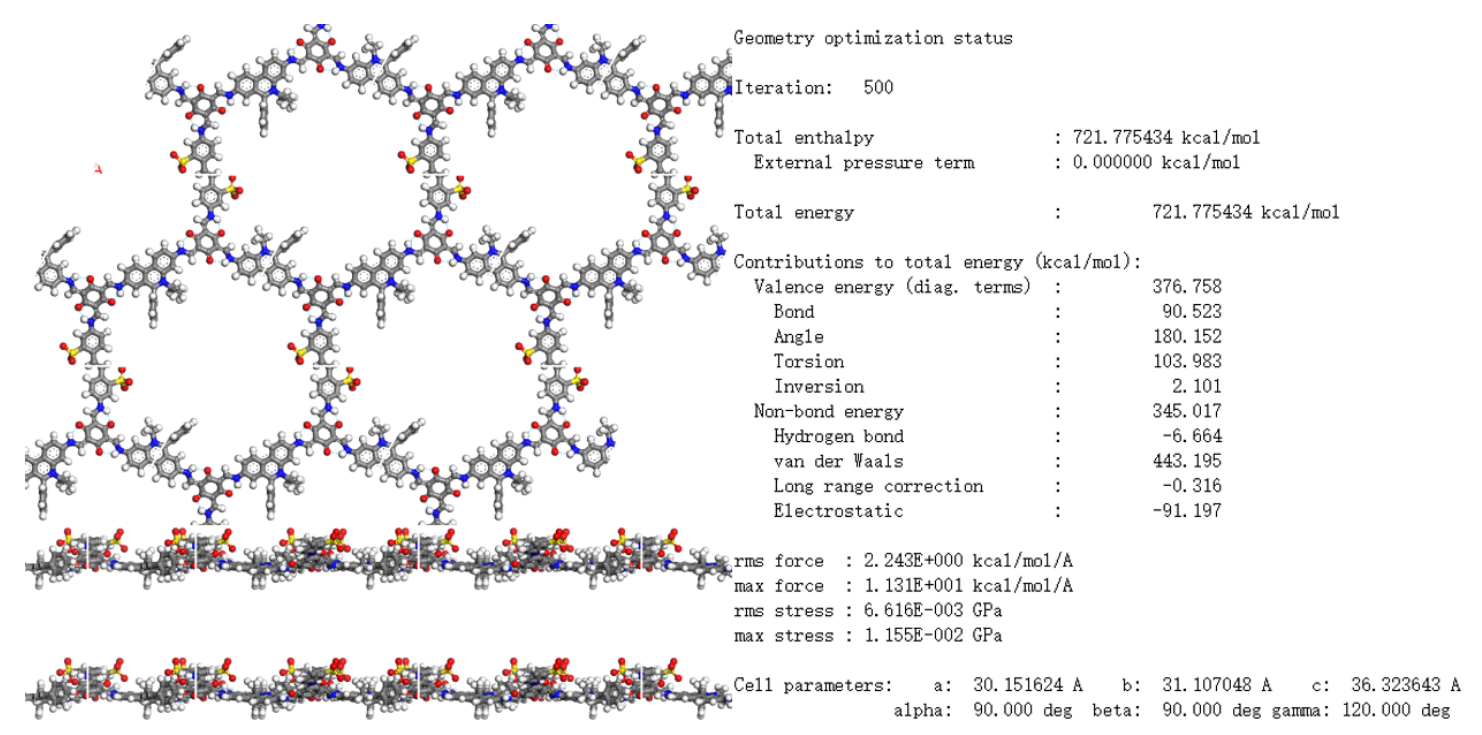

Figure S28. AA stacking structure (top view and side view) of XJCOF-3 and the total energy after geometrical energy minimization.
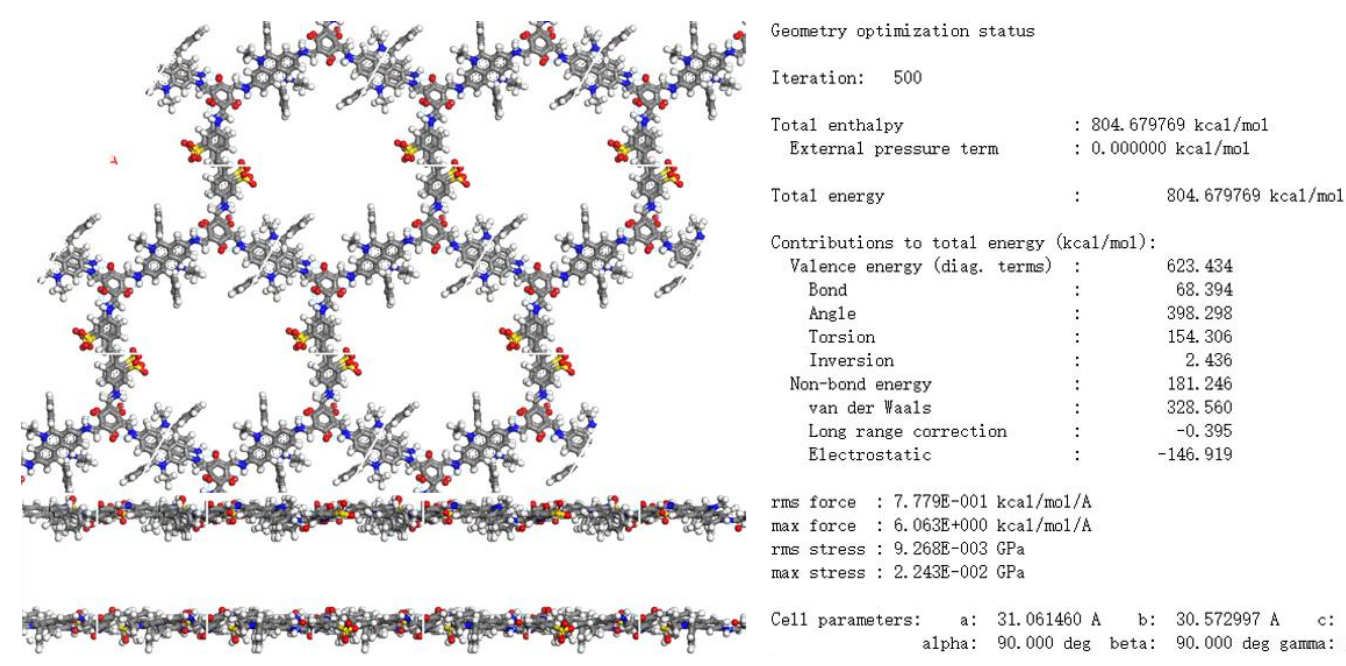

Figure S29. Offset AA stacking structure (top view and side view) of XJCOF3 and the total energy after geometrical energy minimization. 

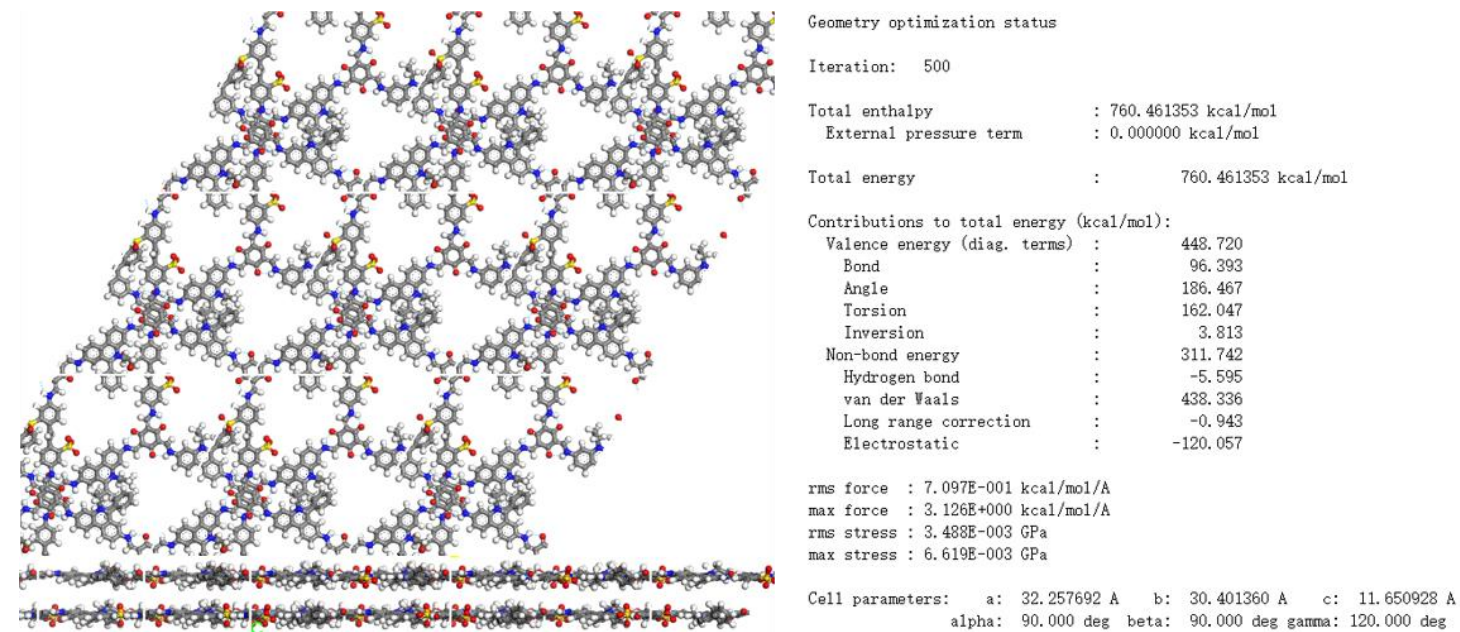

Figure S30. AB stacking structure (top view and side view) of XJCOF-3 and the total energy after geometrical energy minimization.
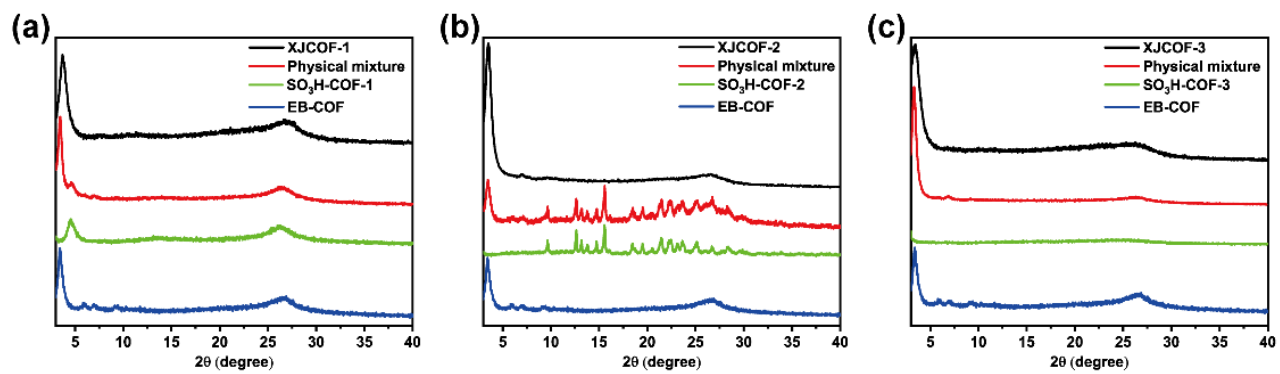

Figure S31. The XRD comparison between the XJCOFs and the physical mixtures of two corresponding individual anionic and cationic COFs. 

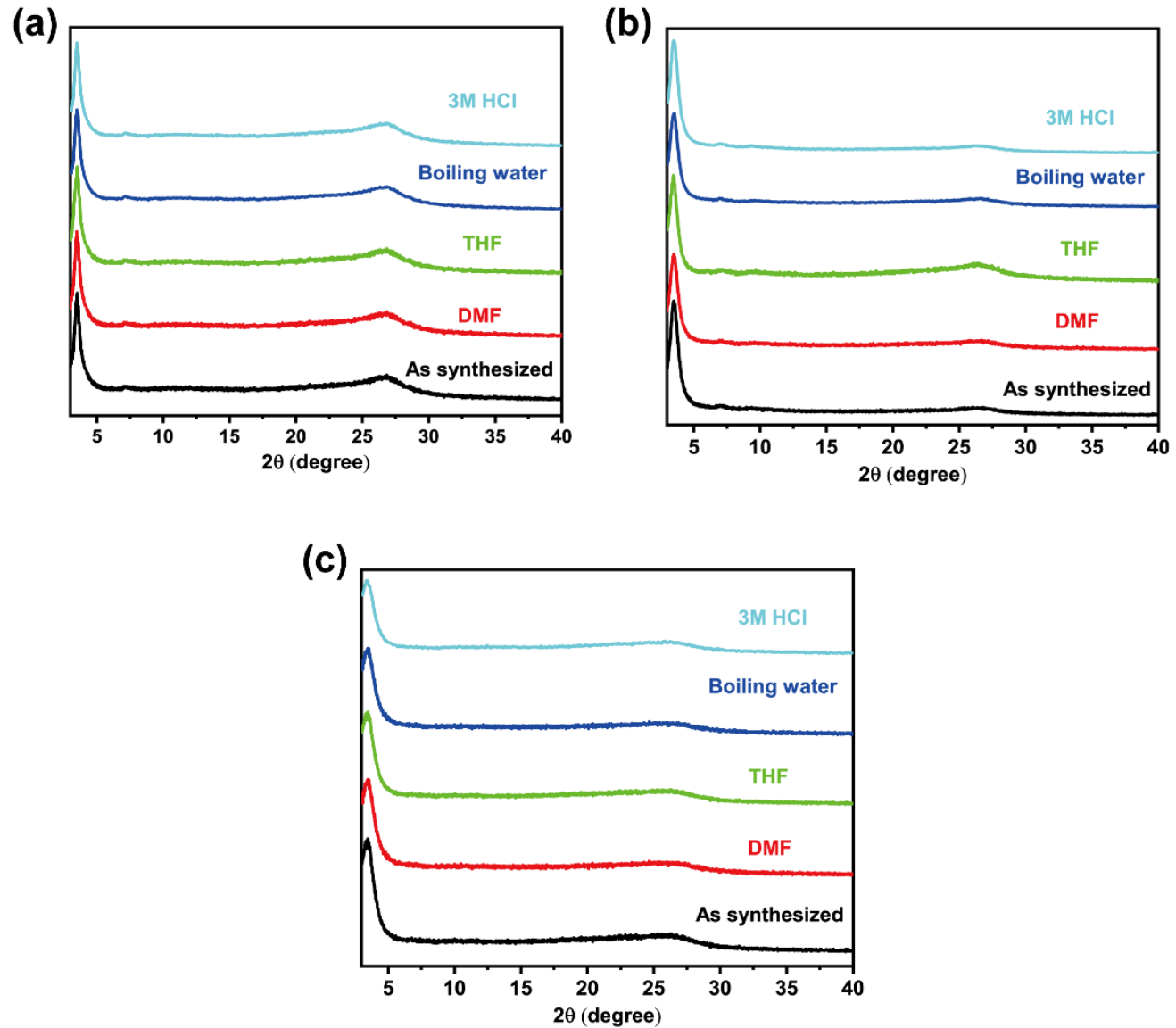

Figure S32. XRD patterns of XJCOF-1(a), XJCOF-2(b), and XJCOF-3(c) upon treatment in different conditions. 
(a)

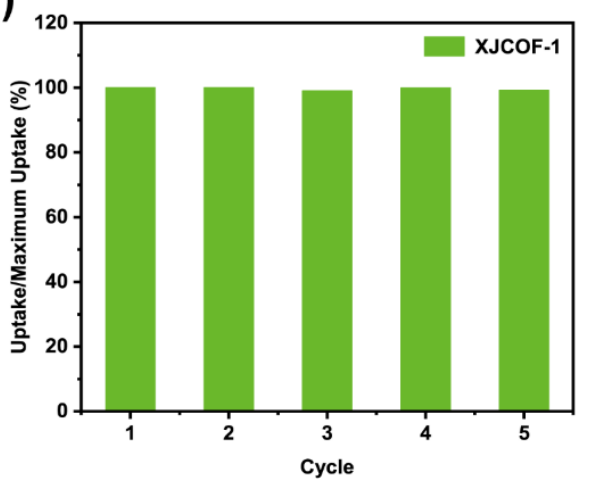

(b)

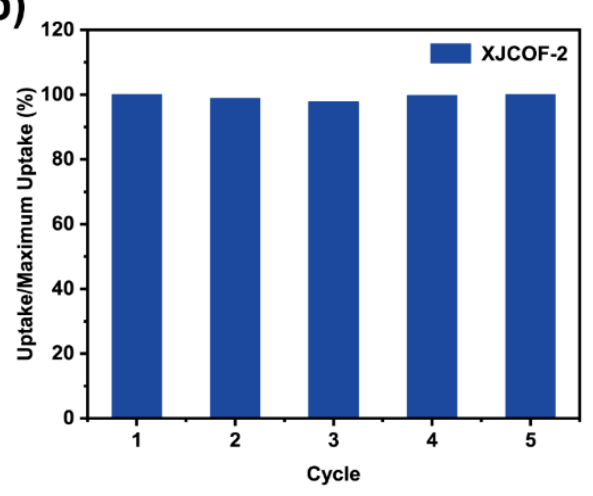

(c)

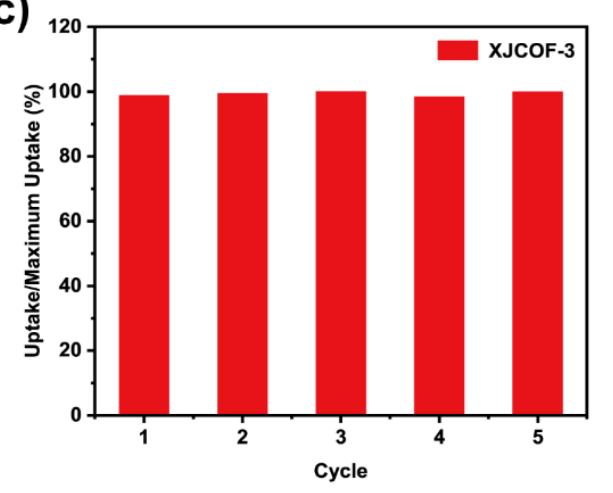

Figure S33. $\mathrm{SO}_{2}$ cycling adsorption-desorption performance of XJCOF-1(a), XJCOF-2(b) and XJCOF-3(c).
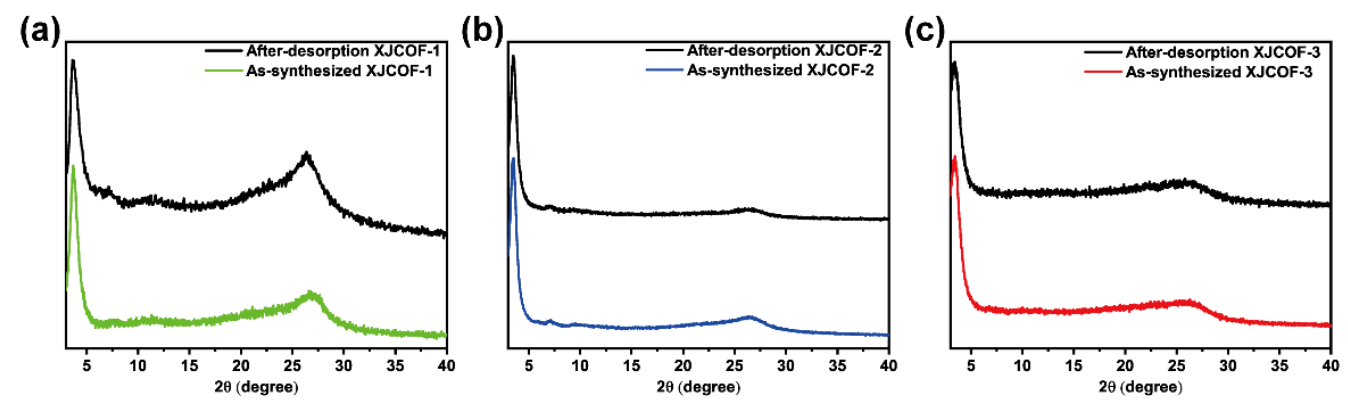

Figure S34. Experimental PXRD data of after-desorption XJCOF vs that of as-synthesized XJCOF in XJCOF-1(a), XJCOF-2(b) and XJCOF-3(c). 


\section{IAST calculations}

The selectivity of $\mathrm{SO}_{2}$ over $\mathrm{CO}_{2}$ in a mixture gas can be defined as:

$$
\mathrm{S}=\left(x_{1} / y_{1}\right) /\left(x_{2} / y_{2}\right)
$$

In the above equation, $x_{1}$ and $y_{1}\left(x_{2}\right.$ and $\left.y_{2}\right)$ are the molar fractions of $\mathrm{SO}_{2}$ $\left(\mathrm{CO}_{2}\right)$ in the adsorbed and bulk phases, respectively. We calculated the values of $x_{1}$ and $x_{2}$ using the Ideal Adsorbed Solution Theory (IAST) of Myers and Prausnitz.
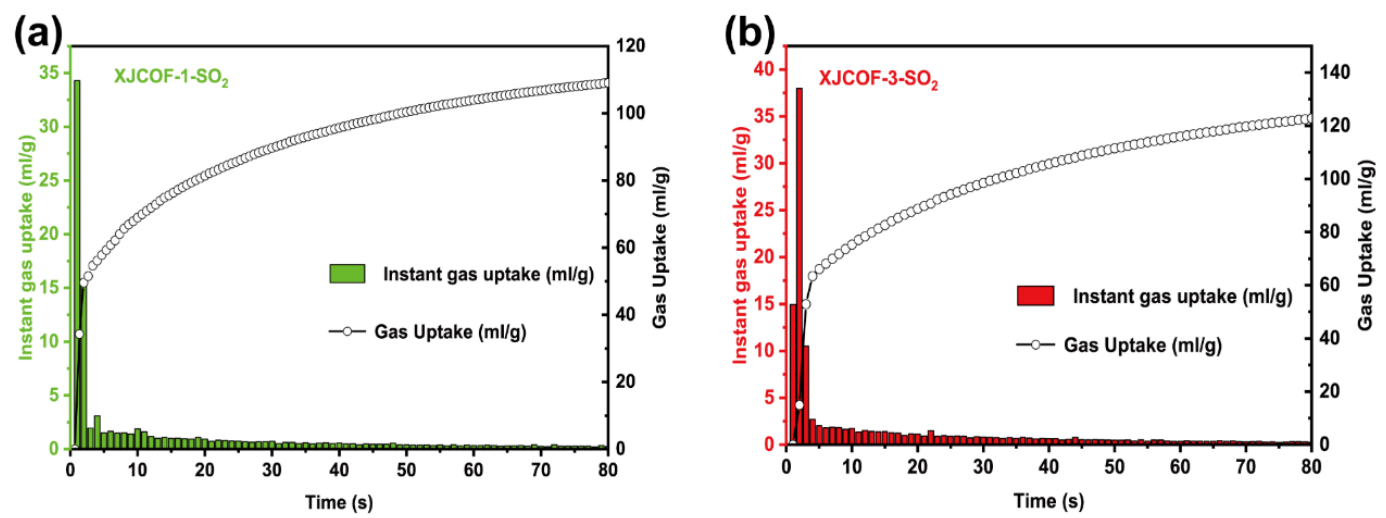

Figure S35. Time-dependent adsorption curves of XJCOF-1(a) and XJCOF3(b) adsorbents for $\mathrm{SO}_{2}$ at $298 \mathrm{~K}$. 
(a)

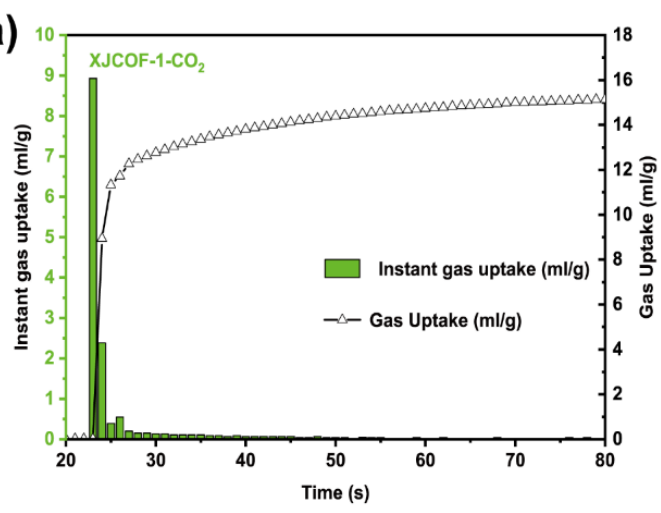

(b)

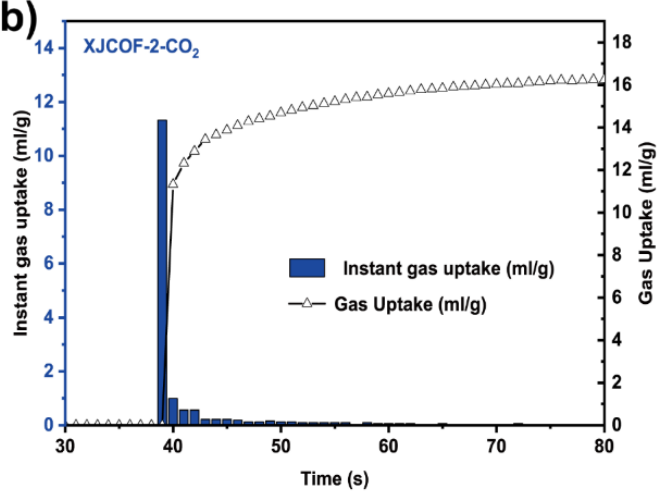

(c)

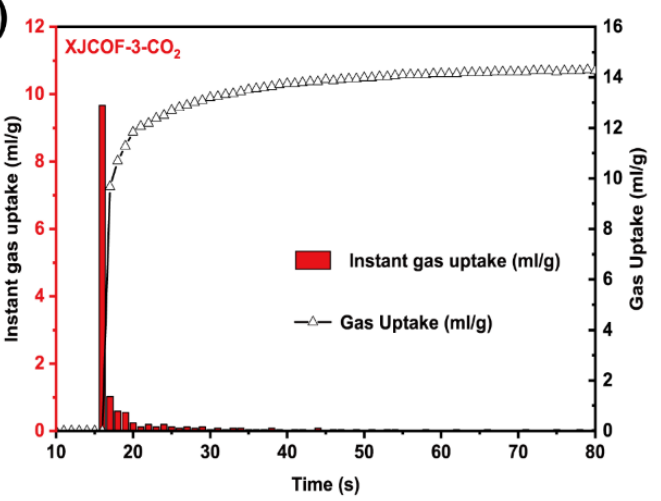

Figure S36. Time-dependent adsorption curves of XJCOF-1(a), XJCOF-2(b) and XJCOF-3(c) adsorbents for $\mathrm{CO}_{2}$ at $298 \mathrm{~K}$.
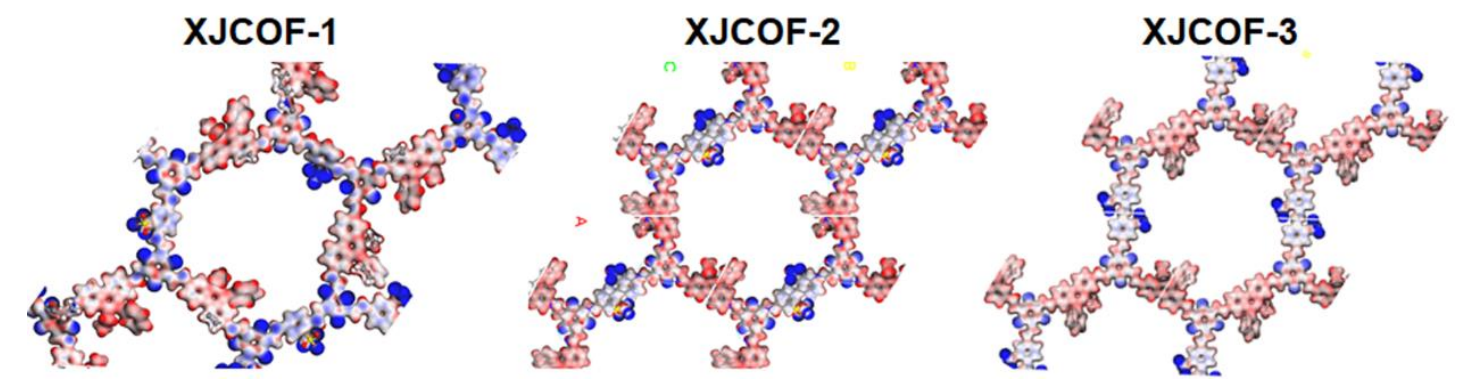

Figure S37. The electron density and electrostatic potential distribution of the XJCOFs framework simulated by DFT. 


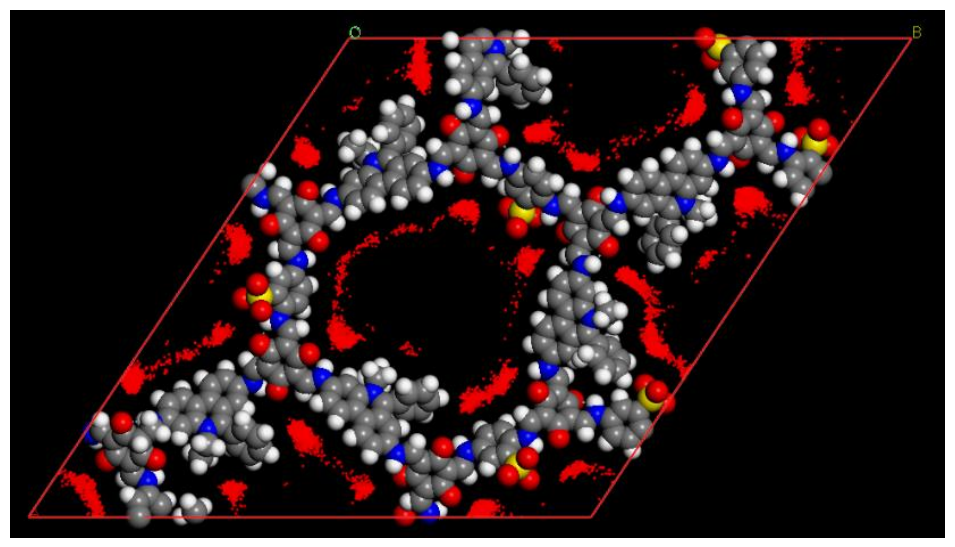

Figure S38. Simulation process of $\mathrm{SO}_{2}$ adsorption in XJCOF-1.

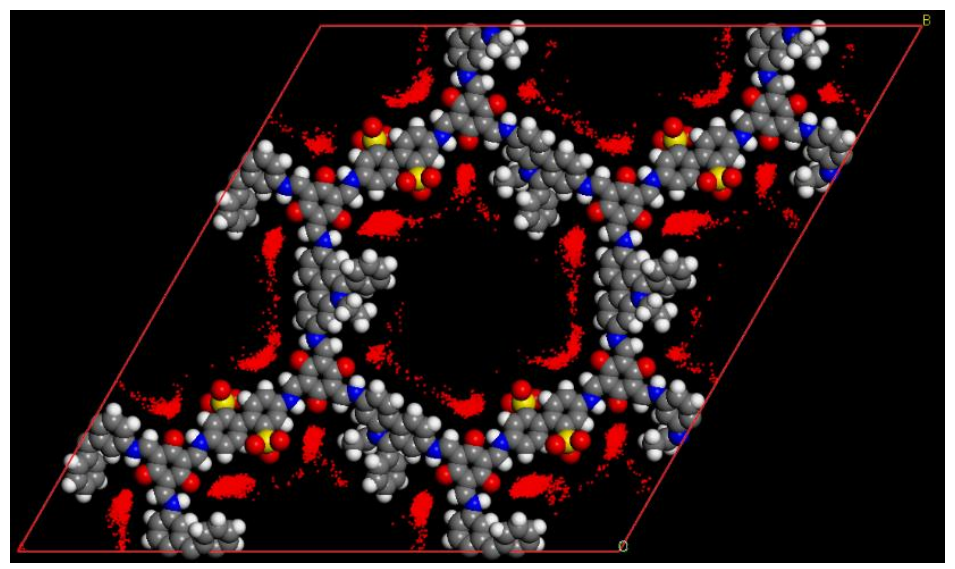

Figure S39. Simulation process of $\mathrm{SO}_{2}$ adsorption in XJCOF-2.

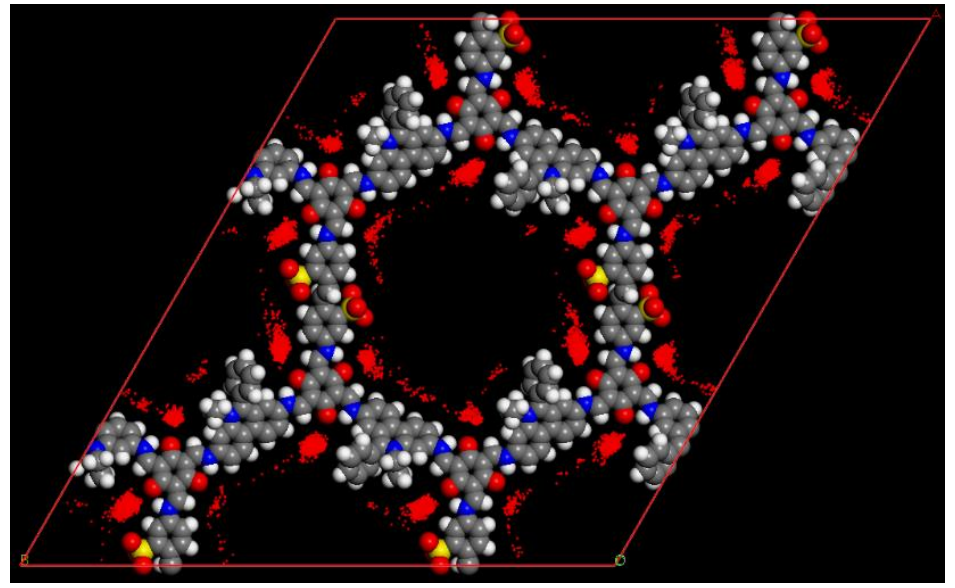

Figure S40. Simulation process of $\mathrm{SO}_{2}$ adsorption in XJCOF-3. 
Table S5. Comparison of $\mathrm{SO}_{2}$ adsorption performance in some reported materials and their $\mathrm{SO}_{2} / \mathrm{CO}_{2}$ selectivity.

\begin{tabular}{|c|c|c|c|c|}
\hline Material & $\begin{array}{l}\mathrm{SO}_{2} \text { uptake } \\
298 \mathrm{k}, 1 \text { bar }\end{array}$ & $\begin{array}{c}\mathrm{SO}_{2} / \mathrm{CO}_{2} \\
\text { selectivity }\end{array}$ & $\begin{array}{c}\mathrm{SO}_{2} / \mathrm{CO} 2 \\
\text { ratio }\end{array}$ & Reference \\
\hline XJCOF-1 & $8.44 \mathrm{mmol} / \mathrm{g}$ & $118(222)$ & 50:50 & This work \\
\hline XJCOF-2 & $9.24 \mathrm{mmol} / \mathrm{g}$ & $39(83)$ & $(10: 90)$ & \\
\hline XJCOF-3 & $9.64 \mathrm{mmol} / \mathrm{g}$ & $42(98)$ & & \\
\hline MFM-300(In) & $8.28 \mathrm{mmol} / \mathrm{g}$ & 50 & $50: 50$ & 1 \\
\hline SIFSIX-2-Cu-i & $11 \mathrm{mmol} / \mathrm{g}$ & 87.1 & 10:90 & 2 \\
\hline MFM-601 & $12.3 \mathrm{mmol} / \mathrm{g}$ & 32 & $50: 50$ & 3 \\
\hline NOTT-300(Al) & $7.1 \mathrm{mmol} / \mathrm{g}$ & & & 4 \\
\hline MFM-300(Sc) & $9.4 \mathrm{mmol} / \mathrm{g}$ & 31 & $20: 80$ & 5 \\
\hline Fe-MIL-127 & $11.7 \mathrm{mmol} / \mathrm{g}$ & 32 & 10:90 & 6 \\
\hline MFM-170 & $17.5 \mathrm{mmol} / \mathrm{g}$ & 35 & $50: 50$ & 7 \\
\hline ECUT-77 & $8.0 \mathrm{mmol} / \mathrm{g}$ & 44 & 1:99 & 8 \\
\hline NOTT-202a & $9.9 \mathrm{mmol} / \mathrm{g}$ & & & 9 \\
\hline $\mathrm{Ni}(\mathrm{bdc})(\mathrm{ted}) 0.5$ & $9.97 \mathrm{mmol} / \mathrm{g}$ & & & 10 \\
\hline Mg-MOF-74 & $8.6 \mathrm{mmol} / \mathrm{g}$ & & & \\
\hline MFM-305 & $7.0 \mathrm{mmol} / \mathrm{g}$ & & & 11 \\
\hline \multirow{3}{*}{$\begin{array}{l}\text { CTF-CSU41 } \\
\text { CTF-CSU38 }\end{array}$} & $6.7 \mathrm{mmol} / \mathrm{g}$ & & & 12 \\
\hline & $4.42 \mathrm{mmol} / \mathrm{g}$ & & & \\
\hline & Dynamic uptake & & & 13 \\
\hline
\end{tabular}




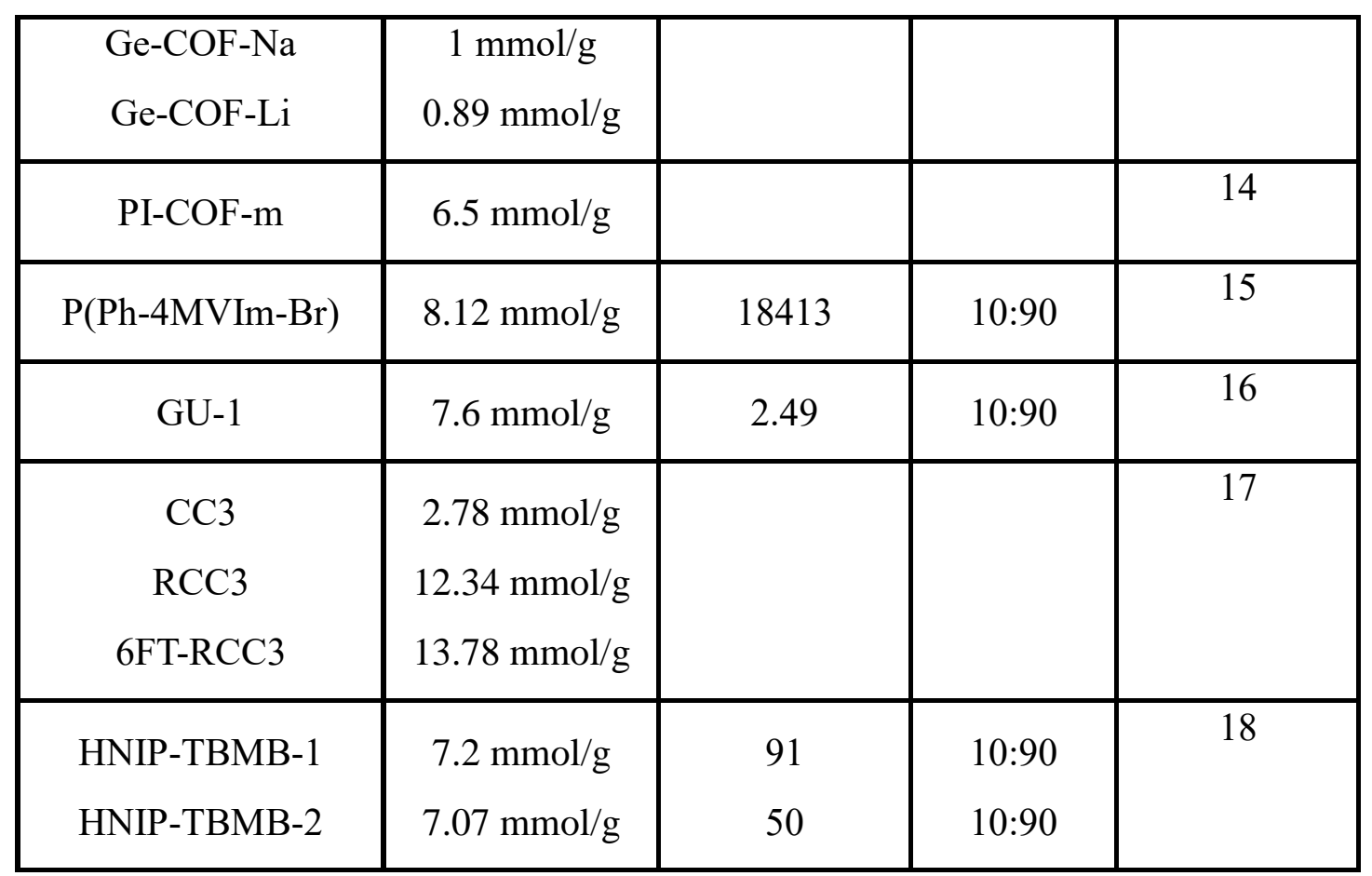


(a)

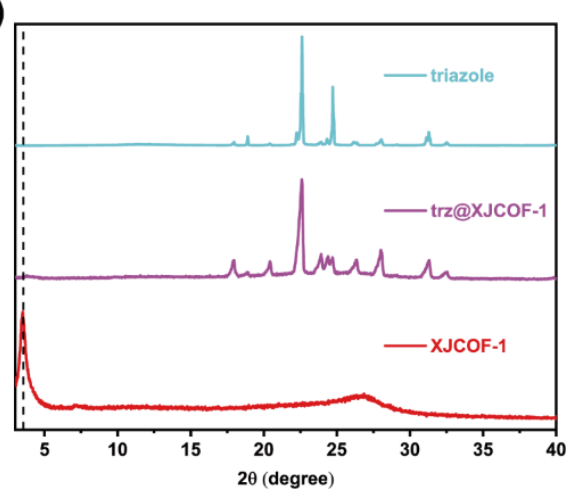

(b)

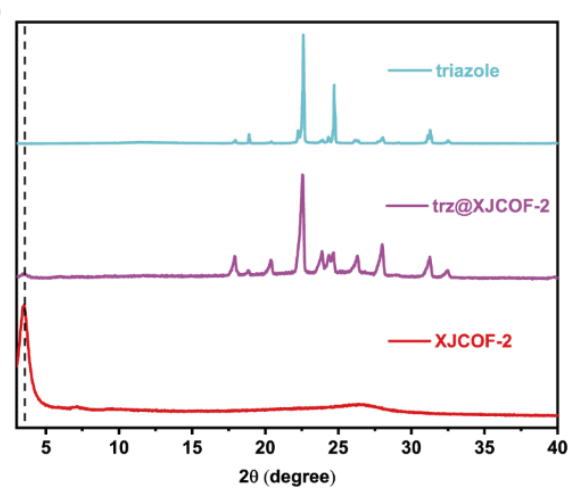

(c)

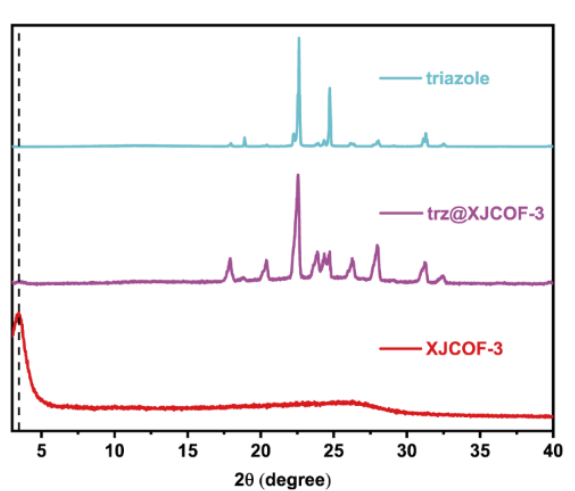

Figure S41. XRD patterns of the XJCOF-1(a), XJCOF-2(b) and XJCOF-3(c) before and after loading triazole. 

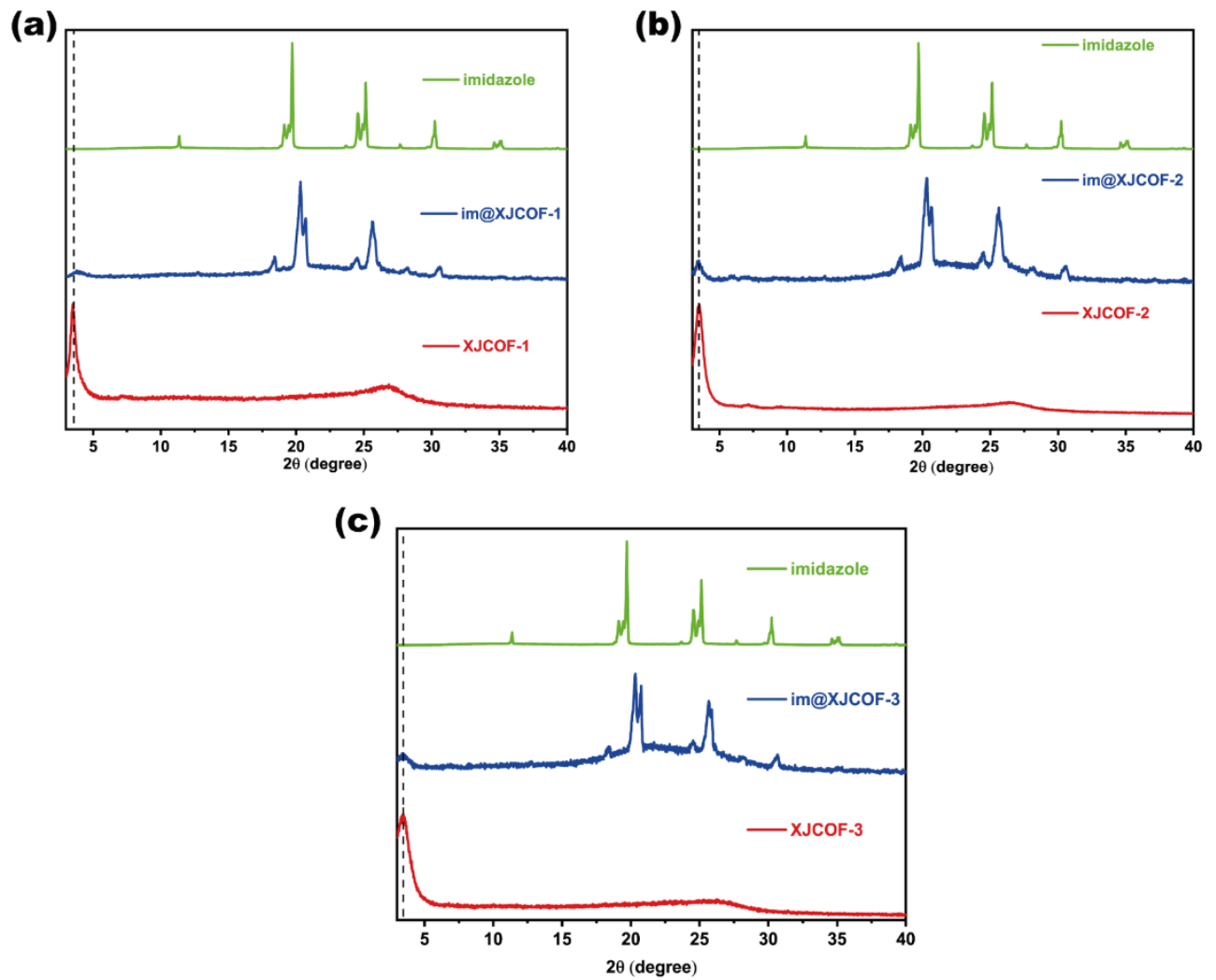

Figure S42. XRD patterns of the XJCOF-1(a), XJCOF-2(b) and XJCOF-3(c) before and after loading imidazole. 

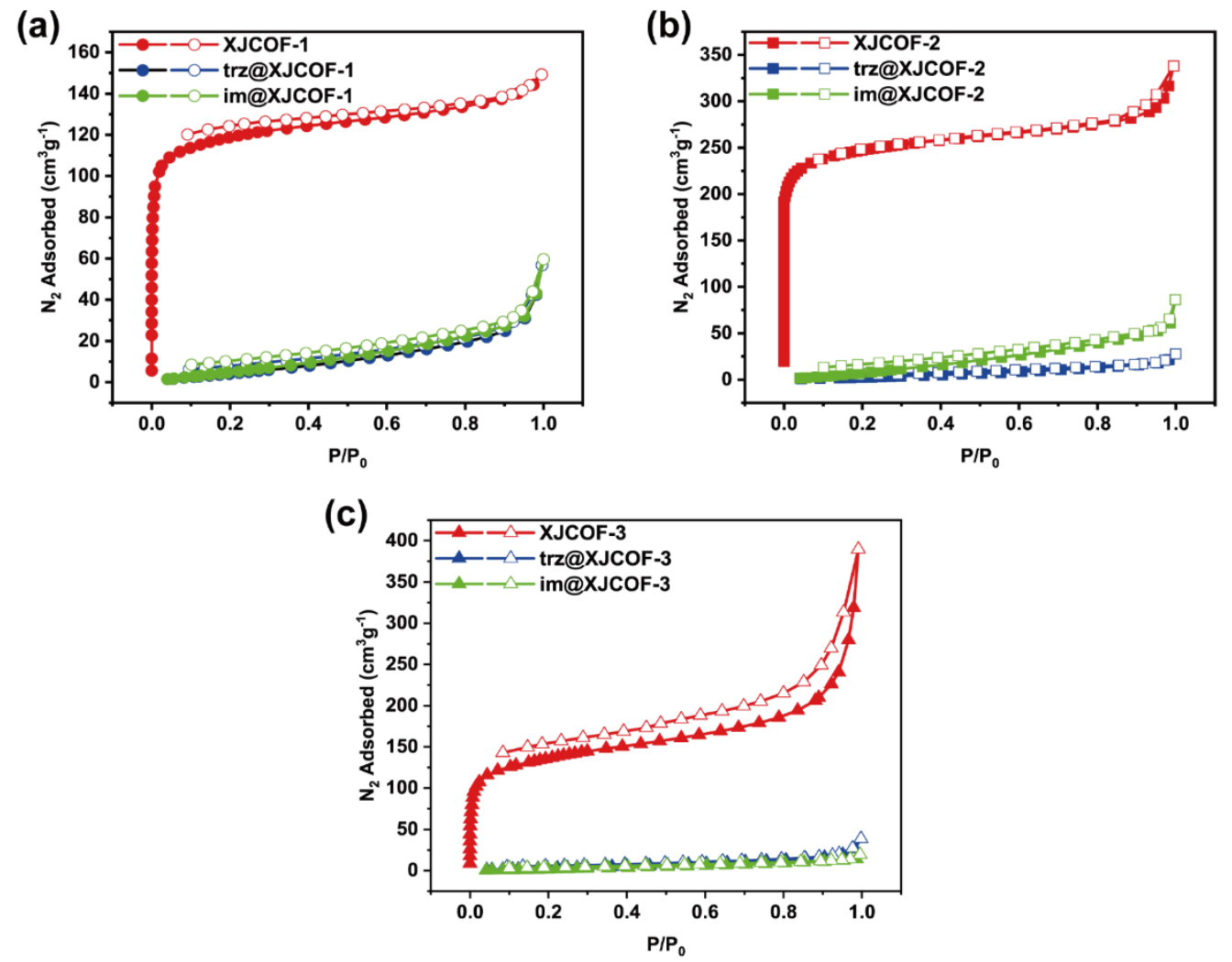

Figure S43. Nitrogen sorption isotherms for (a) XJCOF-1, (b) XJCOF-2 and (c) XJCOF-3 at $77 \mathrm{~K}$ before and after doping triazole and imidazole. 
(a)

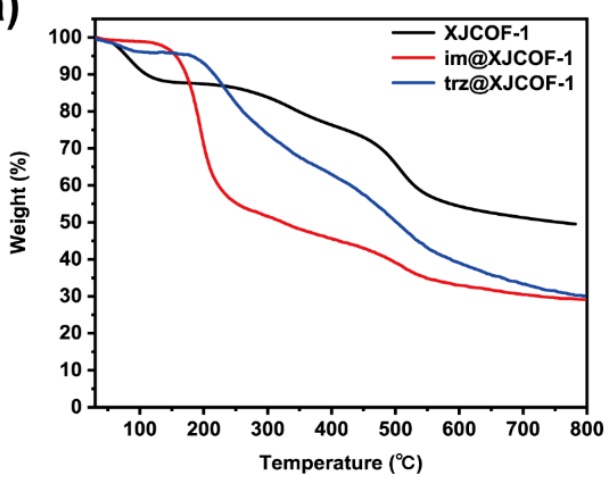

(b)

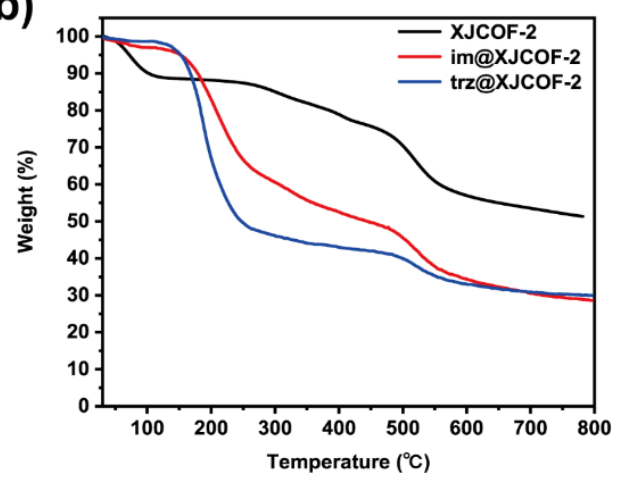

(b)

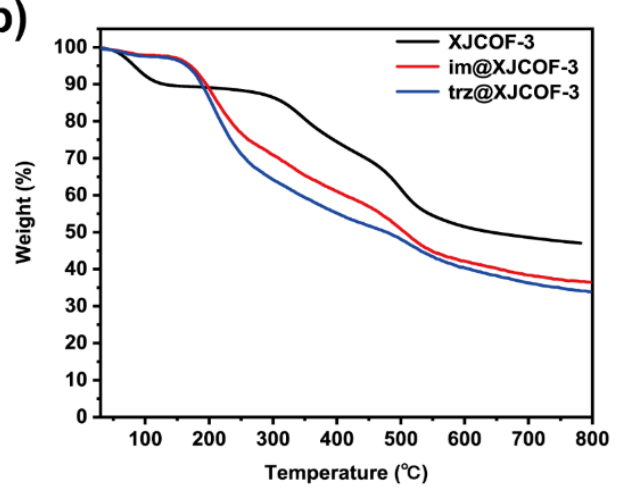

Figure S44. TGA of three pristine COFs(black), im@COFs (red) and trz@COFs (blue): (a)XJCOF-1, (b)XJCOF-2 and (c)XJCOF-3. 
(a)

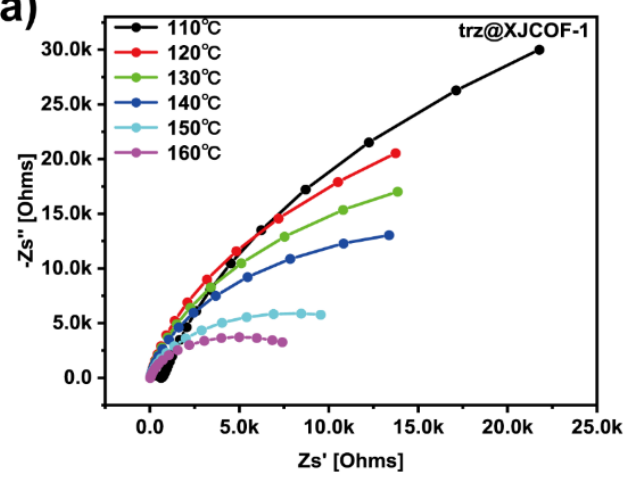

(b)

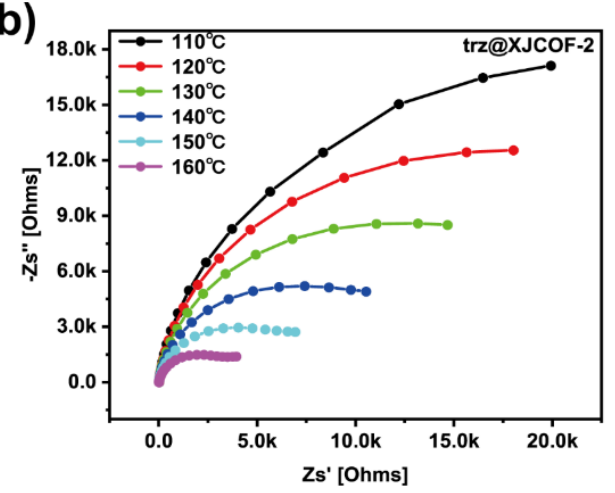

(c)

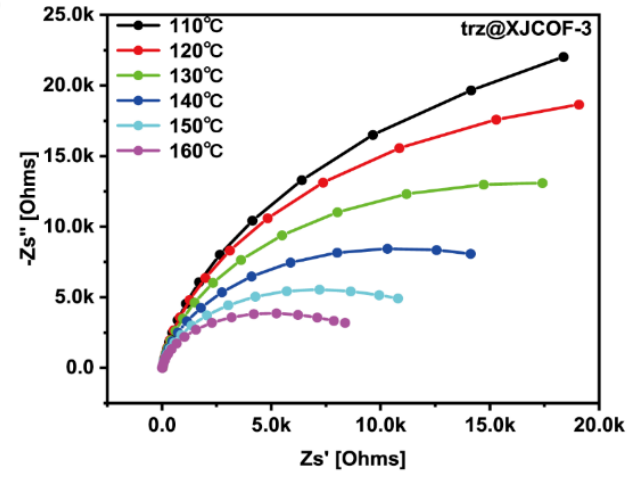

Figure S45. Complete Nyquist of (a)trz@XJCOF-1, (b)trz@XJCOF-2 and (c)trz@XJCOF-3 under anhydrous condition at different temperatures (ranging from $110^{\circ} \mathrm{C}$ to $160^{\circ} \mathrm{C}$ ). 

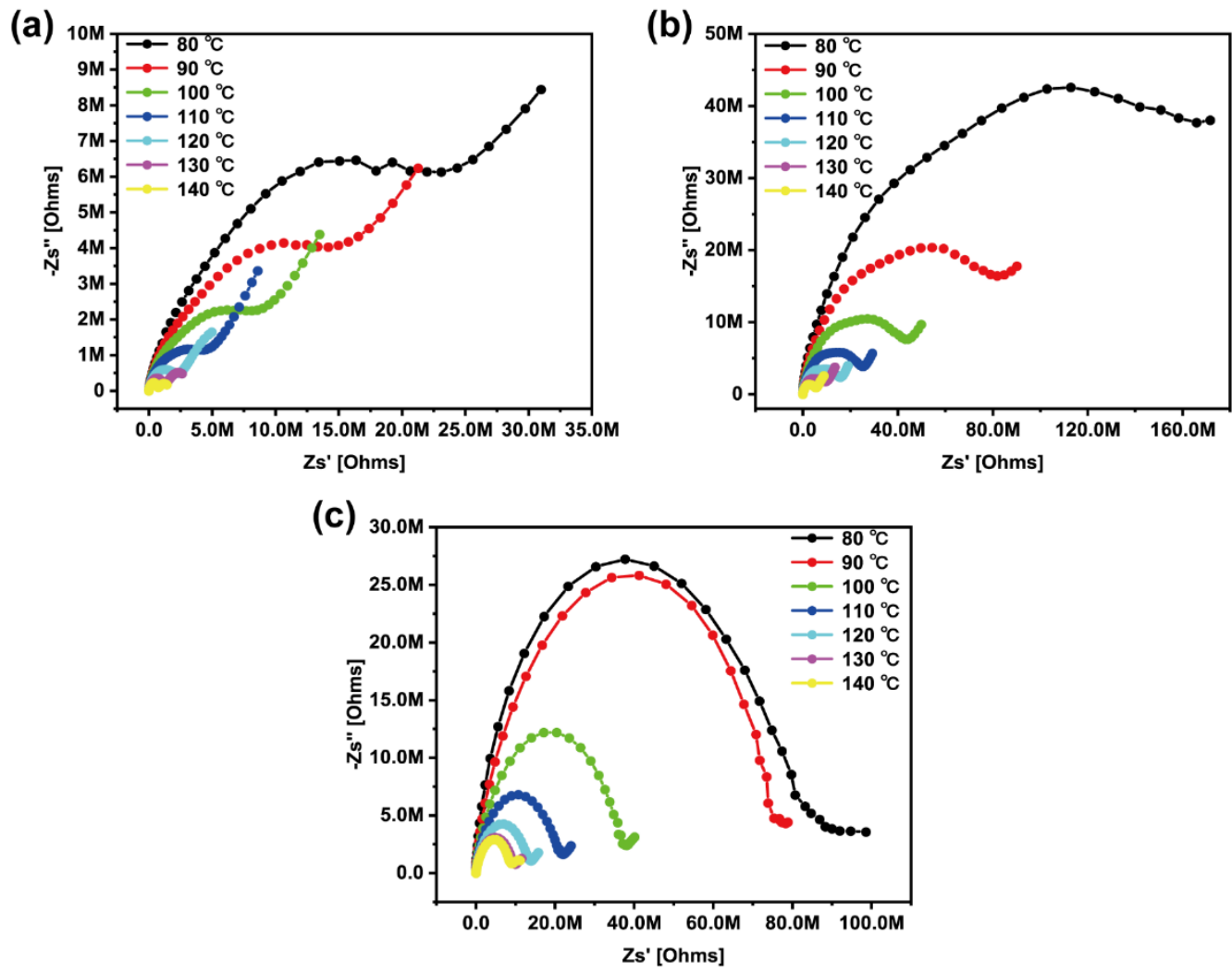

Figure S46. The Nyquist of pristine XJCOFs under anhydrous condition at different temperatures under anhydrous condition. (a) XJCOF-1, (b)XJCOF2 and (c)XJCOF-3. 
(a)

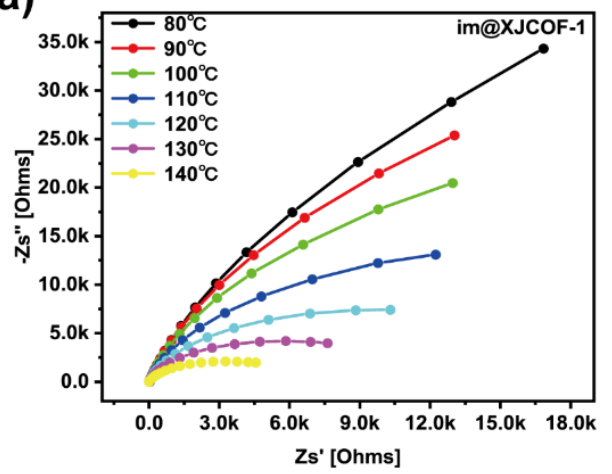

(b)

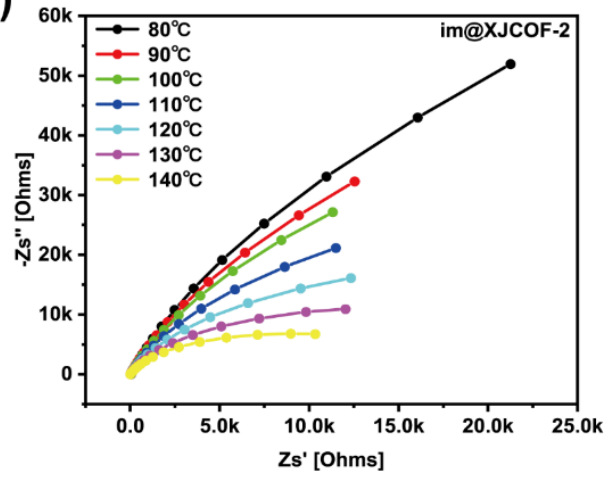

(c)

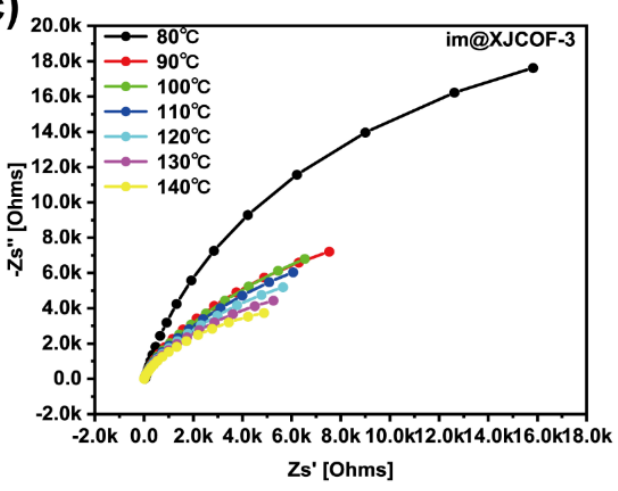

Figure S47. Complete Nyquist of (a)im@XJCOF-1, (b)im@XJCOF-2 and (c)im@XJCOF-3 under anhydrous condition at different temperatures (ranging from $80{ }^{\circ} \mathrm{C}$ to $140{ }^{\circ} \mathrm{C}$ ).

Table S6. The proton conductivity of trz/im@XJCOFs at different temperature and their activation energy.

\begin{tabular}{|c|c|c|c|}
\hline Sample & $\begin{array}{c}\text { Temperature } \\
\text { (K) }\end{array}$ & $\begin{array}{c}\text { Proton } \\
\text { Conductivity } \\
\left(\mathbf{S ~ c m}^{-1}\right)\end{array}$ & $\begin{array}{c}\text { Activation Energy } \\
\text { (eV) }\end{array}$ \\
\hline \multirow{4}{*}{ trz@XJCOF-1 } & 393 & $2.82 \times 10^{-3}$ & \multirow{2}{*}{0.245} \\
\cline { 2 - 3 } & 403 & $3.31 \times 10^{-3}$ & \multirow{2}{*}{} \\
\cline { 2 - 3 } & 413 & $4.01 \times 10^{-3}$ & \multicolumn{1}{|c}{} \\
\cline { 2 - 3 } & $\mathbf{4 2 3}$ & $\mathbf{4 . 3 \times \mathbf { 1 0 } ^ { - 3 }}$ & \\
\cline { 2 - 3 } & 433 & $3.34 \times 10^{-3}$ & \\
\hline
\end{tabular}




\begin{tabular}{|c|c|c|c|}
\hline \multirow[t]{6}{*}{ trz@XJCOF-2 } & 383 & $5.84 \times 10^{-3}$ & \multirow[t]{6}{*}{0.265} \\
\hline & 393 & $6.91 \times 10^{-3}$ & \\
\hline & 403 & $8.21 \times 10^{-3}$ & \\
\hline & 413 & $9.86 \times 10^{-3}$ & \\
\hline & 423 & $1.14 \times 10^{-2}$ & \\
\hline & 433 & $1.29 \times 10^{-2}$ & \\
\hline \multirow[t]{6}{*}{ trz@XJCOF-3 } & 383 & $2.37 \times 10^{-3}$ & \multirow[t]{6}{*}{0.28} \\
\hline & 393 & $2.88 \times 10^{-3}$ & \\
\hline & 403 & $3.5 \times 10^{-3}$ & \\
\hline & 413 & $4.17 \times 10^{-3}$ & \\
\hline & 423 & $4.94 \times 10^{-3}$ & \\
\hline & 433 & $5.6 \times 10^{-3}$ & \\
\hline \multirow[t]{7}{*}{ im@XJCOF-1 } & 353 & $2.66 \times 10^{-3}$ & \multirow[t]{7}{*}{0.21} \\
\hline & 363 & $2.26 \times 10^{-2}$ & \\
\hline & 373 & $2.69 \times 10^{-2}$ & \\
\hline & 383 & $3.14 \times 10^{-2}$ & \\
\hline & 393 & $3.61 \times 10^{-2}$ & \\
\hline & 403 & $4.10 \times 10^{-2}$ & \\
\hline & 413 & $4.38 \times 10^{-2}$ & \\
\hline \multirow[t]{7}{*}{ im@XJCOF-2 } & 353 & $3.04 \times 10^{-3}$ & \multirow[t]{7}{*}{0.243} \\
\hline & 363 & $1.49 \times 10^{-2}$ & \\
\hline & 373 & $1.77 \times 10^{-2}$ & \\
\hline & 383 & $2.12 \times 10^{-2}$ & \\
\hline & 393 & $2.49 \times 10^{-2}$ & \\
\hline & 403 & $2.89 \times 10^{-2}$ & \\
\hline & 413 & $3.33 \times 10^{-2}$ & \\
\hline \multirow[t]{7}{*}{ im@XJCOF-3 } & 353 & $4.49 \times 10^{-3}$ & \multirow[t]{7}{*}{0.2} \\
\hline & 363 & $1.26 \times 10^{-2}$ & \\
\hline & 373 & $1.47 \times 10^{-2}$ & \\
\hline & 383 & $1.69 \times 10^{-2}$ & \\
\hline & 393 & $1.92 \times 10^{-2}$ & \\
\hline & 403 & $2.15 \times 10^{-2}$ & \\
\hline & 413 & $2.43 \times 10^{-2}$ & \\
\hline
\end{tabular}


Table S7. Comparison of proton conductivities in some reported COFs and MOFs under anhydrous condition.

\begin{tabular}{|c|c|c|c|c|c|}
\hline Material & $\begin{array}{l}\text { Proton } \\
\text { carriers }\end{array}$ & $\begin{array}{l}\text { Conductivity } \\
\qquad\left(\mathrm{S} \mathrm{cm}^{-1}\right)\end{array}$ & $\begin{array}{c}\text { Ea } \\
(\mathrm{eV})\end{array}$ & Condition & References \\
\hline $\begin{array}{l}\operatorname{trz} @ X J C O F-1 \\
\operatorname{trz} @ X J C O F-2 \\
\operatorname{trz} @ X J C O F-3 \\
\text { im@XJCOF-1 } \\
\text { im@XJCOF-2 } \\
\text { im@XJCOF-3 }\end{array}$ & $\begin{array}{c}\text { triazole/ } \\
\text { imidazole }\end{array}$ & $\begin{array}{l}4.3 \times 10^{-3} \\
1.29 \times 10^{-2} \\
5.6 \times 10^{-3} \\
4.38 \times 10^{-2} \\
3.33 \times 10^{-2} \\
2.43 \times 10^{-2}\end{array}$ & $\begin{array}{c}0.245 \\
0.265 \\
0.28 \\
0.21 \\
0.243 \\
0.2\end{array}$ & $\begin{array}{l}150^{\circ} \mathrm{C} \text {, anhyrous } \\
160^{\circ} \mathrm{C} \text {, anhyrous } \\
160^{\circ} \mathrm{C} \text {, anhyrous } \\
140^{\circ} \mathrm{C} \text {, anhyrous } \\
140^{\circ} \mathrm{C} \text {, anhyrous } \\
140^{\circ} \mathrm{C} \text {, anhyrous }\end{array}$ & This work \\
\hline $\begin{array}{c}\text { tra@TAP-COF } \\
\text { tra@PD-COF } \\
\text { tra@DAAQ- } \\
\text { COF } \\
\text { tra@EB-COF }\end{array}$ & triazole & $\begin{array}{l}3.82 \times 10^{-3} \\
4.98 \times 10^{-5} \\
2.62 \times 10^{-5} \\
3.25 \times 10^{-3}\end{array}$ & $\begin{array}{l}0.26 \\
0.34 \\
0.32 \\
0.22\end{array}$ & $\begin{array}{l}150^{\circ} \mathrm{C} \text {, anhydrous } \\
140^{\circ} \mathrm{C} \text {, anhydrous } \\
140^{\circ} \mathrm{C} \text {, anhydrous } \\
160^{\circ} \mathrm{C} \text {, anhydrous }\end{array}$ & 19 \\
\hline $\begin{array}{l}\text { im@TPB- } \\
\text { DMTP-COF } \\
\text { trz@TPB- } \\
\text { DMTP-COF }\end{array}$ & $\begin{array}{l}\text { imidazole/ } \\
\text { triazole }\end{array}$ & $\begin{array}{c}4.37 \times 10^{-3} \\
1.1 \times 10^{-3}\end{array}$ & $\begin{array}{l}0.38 \\
0.21\end{array}$ & $\begin{array}{l}130^{\circ} \mathrm{C} \text {, anhydrous } \\
130^{\circ} \mathrm{C} \text {, anhydrous }\end{array}$ & 20 \\
\hline $\begin{array}{c}\text { im@Td-PPI } \\
\text { im@Td-PNDI }\end{array}$ & imidazole & $\begin{array}{l}3.49 \times 10^{-4} \\
9.04 \times 10^{-5}\end{array}$ & $\begin{array}{c}0.3 \\
0.33\end{array}$ & $\begin{array}{l}90^{\circ} \mathrm{C}, \text { anhydrous } \\
90^{\circ} \mathrm{C} \text {, anhydrous }\end{array}$ & 21 \\
\hline $\begin{array}{l}\text { Py-BT-COF-50 } \\
\text { Py-TT-COF-50 } \\
\text { Py-BD-COF-50 }\end{array}$ & imidazole & $\begin{array}{l}2.92 \times 10-3 \\
3.08 \times 10-3 \\
8.20 \times 10-4\end{array}$ & $\begin{array}{l}0.31 \\
0.31 \\
0.32\end{array}$ & $130^{\circ} \mathrm{C}$, anhydrous & 22 \\
\hline $\begin{array}{l}\text { 1دIm } \\
\text { 2つIm }\end{array}$ & imidazole & $\begin{array}{l}2.2 \times 10^{-5} \\
1.0 \times 10^{-7}\end{array}$ & $\begin{array}{l}0.6 \\
0.9\end{array}$ & $\begin{array}{l}120^{\circ} \mathrm{C} \text {, anhydrous } \\
120^{\circ} \mathrm{C} \text {, anhydrous }\end{array}$ & 23 \\
\hline
\end{tabular}




\begin{tabular}{|c|c|c|c|c|c|}
\hline $\begin{array}{c}{\left[\mathrm{Zn}\left(\mathrm{H}_{2} \mathrm{PO}_{4}\right)_{2}(\mathrm{Tz}\right.} \\
\mathrm{H})]_{\mathrm{n}}\end{array}$ & triazole & $1.2 \times 10^{-4}$ & 0.6 & $150^{\circ} \mathrm{C}$, anhydrous & 24 \\
\hline $\begin{array}{c}\beta- \\
\text { PCMOF2(Tz) }\end{array}$ & triazole & $2.0 \times 10^{-4}$ & 0.51 & $150^{\circ} \mathrm{C}$, anhydrous & 25 \\
\hline Im-in-MOF-217 & imidazole & $1.1 \times 10^{-3}$ & 0.58 & $100^{\circ} \mathrm{C}$, anhydrous & 26 \\
\hline im@UiO-67 & imidazole & $1.4 \times 10^{-3}$ & 0.36 & $120^{\circ} \mathrm{C}$, anhydrous & 27 \\
\hline CAU-11_HIm & imidazole & $3.0 \times 10^{-4}$ & 0.19 & $110^{\circ} \mathrm{C}$, anhydrous & 28 \\
\hline $\begin{array}{l}\mathrm{H}_{3} \mathrm{PO}_{4} @ \text { TPB- } \\
\text { DMeTP-COF }\end{array}$ & $\begin{array}{l}\text { phosphoric } \\
\text { acid }\end{array}$ & $1.91 \times 10^{-1}$ & 0.34 & $160^{\circ} \mathrm{C}$, anhydrous & 29 \\
\hline COF-F6-H & $\begin{array}{l}\text { phosphoric } \\
\text { acid }\end{array}$ & $4.2 \times 10^{-2}$ & $\begin{array}{c}0.09- \\
0.54\end{array}$ & $140^{\circ} \mathrm{C}$, anhydrous & 30 \\
\hline CTF-M5 & $\begin{array}{l}\text { trifluorom } \\
\text { ethanesulf } \\
\text { onic acid }\end{array}$ & $3.24 \times 10^{-2}$ & 0.11 & $100^{\circ} \mathrm{C}$, anhydrous & 31 \\
\hline $\begin{array}{c}\text { phytic@TpPa- } \\
\text { Py } \\
\text { phytic@TpPa- } \\
\mathrm{SO}_{3} \mathrm{H}\end{array}$ & phytic acid & $\begin{array}{l}3.00 \times 10^{-4} \\
7.5 \times 10^{-5}\end{array}$ & $\begin{array}{c}0.1 \\
0.16\end{array}$ & $\begin{array}{l}120^{\circ} \mathrm{C} \text {, anhydrous } \\
120^{\circ} \mathrm{C} \text {, anhydrous }\end{array}$ & 32 \\
\hline $\begin{array}{l}\text { PA@TpBpy-MT } \\
\text { PA@TpBpy-ST }\end{array}$ & $\begin{array}{l}\text { phosphoric } \\
\text { acid }\end{array}$ & $\begin{array}{l}2.5 \times 10^{-3} \\
1.98 \times 10^{-3}\end{array}$ & $\begin{array}{l}0.11 \\
0.12\end{array}$ & $120^{\circ} \mathrm{C}$, anhydrous & 33 \\
\hline PA@Tp-Azo & $\begin{array}{l}\text { phosphoric } \\
\text { acid }\end{array}$ & $6.7 \times 10^{-5}$ & 0.11 & $67^{\circ} \mathrm{C}$, anhydrous & 34 \\
\hline
\end{tabular}


(a)

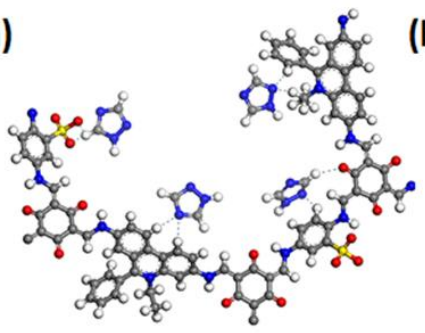

(d)

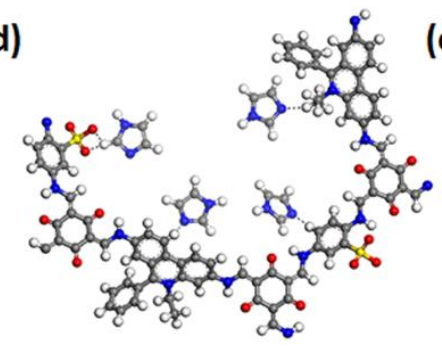

(b)

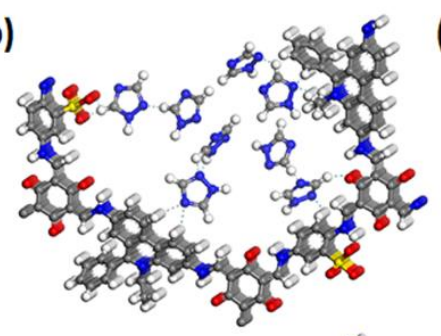

(e)

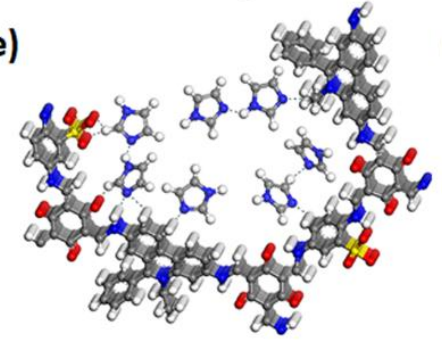

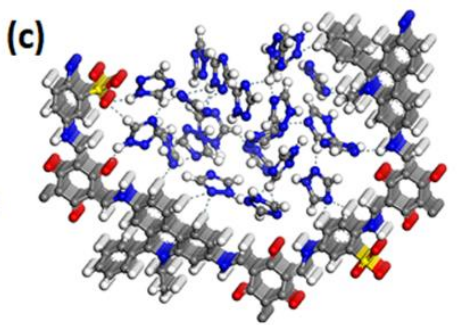

(f)

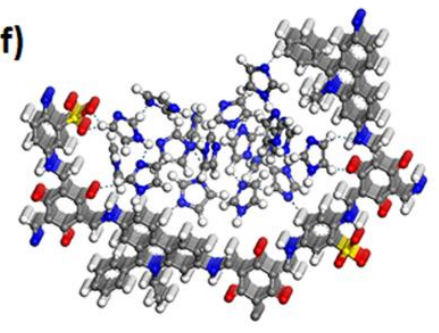

Figure S48. Arrangement of (a)single-layered and (b)double-layered triazole molecular in XJCOF-1, (c)Graphic representations of triazole and hydrogenbonding nets in XJCOF-1; Arrangement of (d)single-layered and (e)doublelayered imidazole molecular in XJCOF-1, (f)Graphic representations of imidazole and hydrogen-bonding nets in XJCOF-1.

(a)

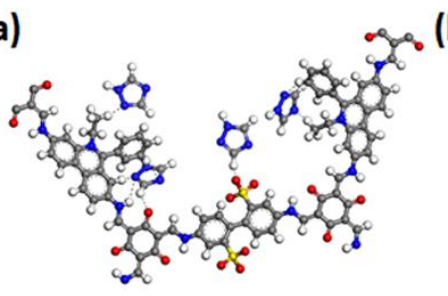

(b)

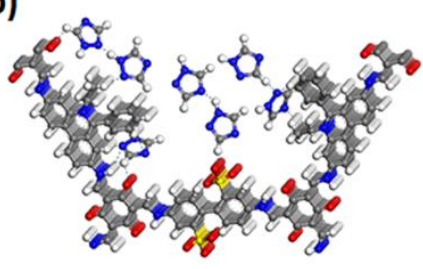

(c)

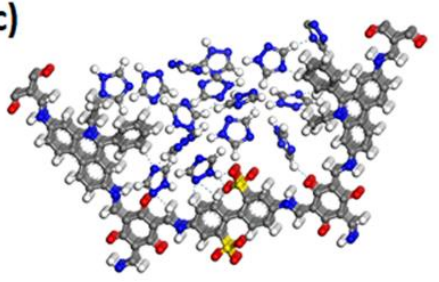

Figure S49. Arrangement of (a)single-layered and (b)double-layered triazole molecular in XJCOF-2, (c)Graphic representations of triazole and hydrogenbonding nets in XJCOF-2. 
(a)

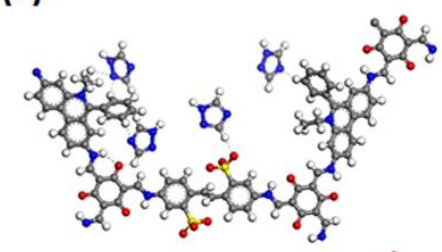

(d)

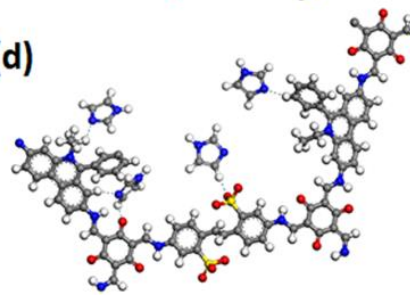

(b)

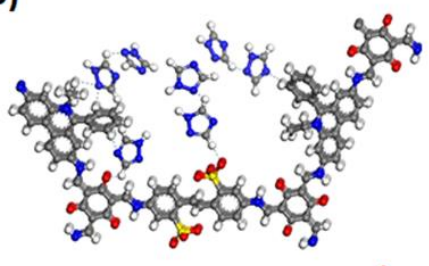

(c)
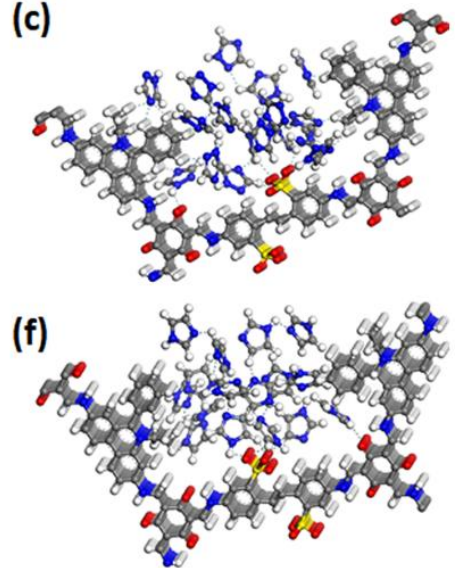

Figure S50. Arrangement of (a)single-layered and (b)double-layered triazole molecular in XJCOF-3, (c)Graphic representations of triazole and hydrogenbonding nets in XJCOF-3; Arrangement of (d)single-layered and (e)doublelayered imidazole molecular in XJCOF-3, (f)Graphic representations of imidazole and hydrogen-bonding nets in XJCOF-3.

Table S8. Proton dissociation energy of energy of trz@XJCOFs and im@XJCOFs

\begin{tabular}{|l|l|l|l|}
\hline Proton dissociation energy & \multicolumn{2}{l}{ Entry } & eV \\
Entry & eV & Imidazole & 4.8 \\
\hline Triazole & 5 & im@XJCOF-1 & 4.1 \\
\hline trz@XJCOF-1 & 3.2 & im@XJCOF-2 & 4 \\
\hline trz@XJCOF-2 & 4.1 & im@XJCOF-3 & 4 \\
\hline trz@XJCOF-3 & 2.8 & &
\end{tabular}


(a)

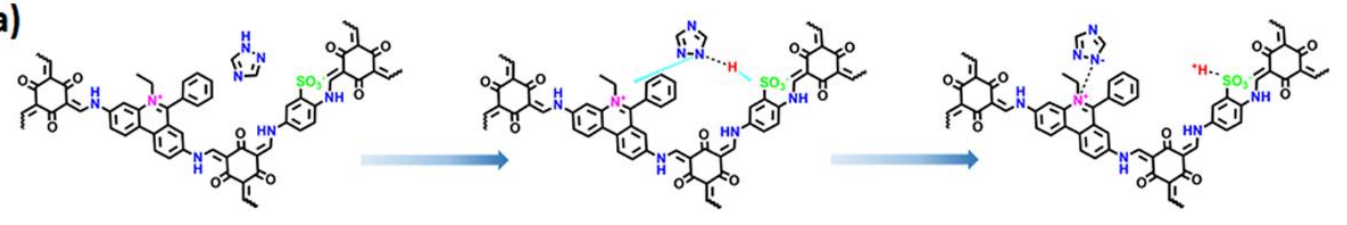

(b)

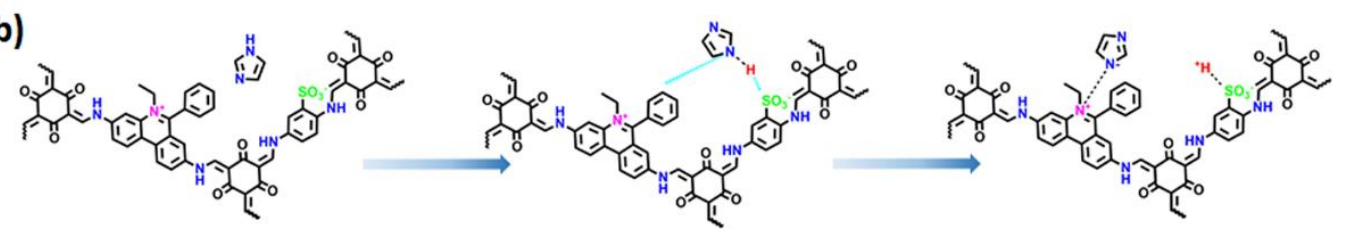

Figure S51. Graphic representations of proton dissociation energy values for (a)trz@XJCOF-1 and (b)im@XJCOF-1.

(a)

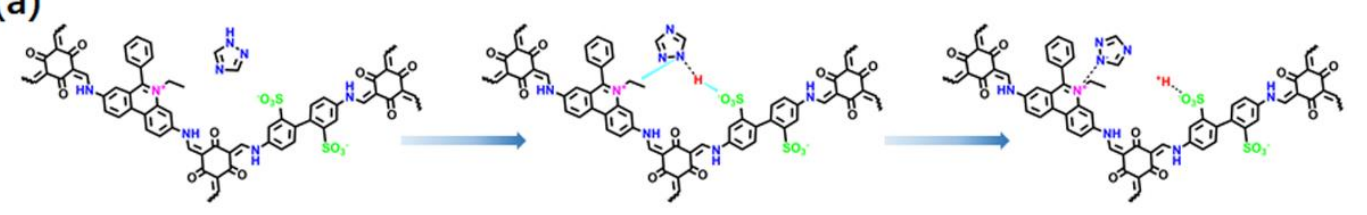

(b)

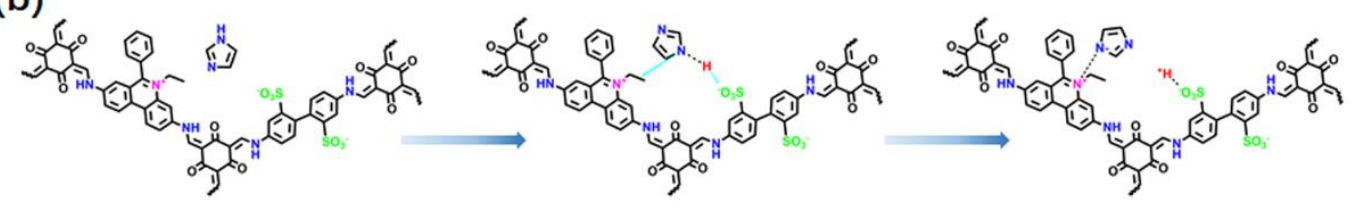

Figure S52. Graphic representations of proton dissociation energy values for (a)trz@XJCOF-2 and (b)im@XJCOF-2.

(a)

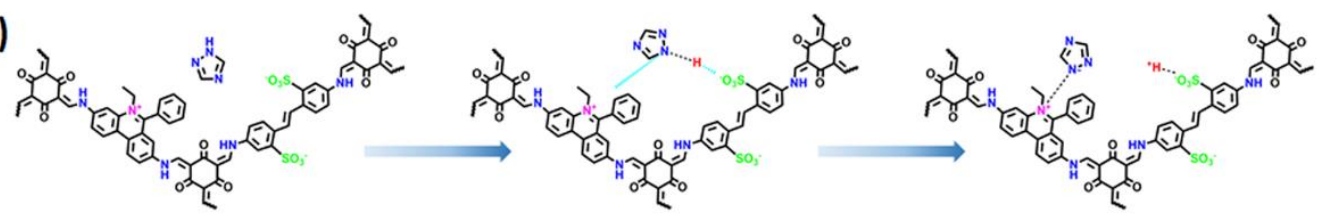

(b)

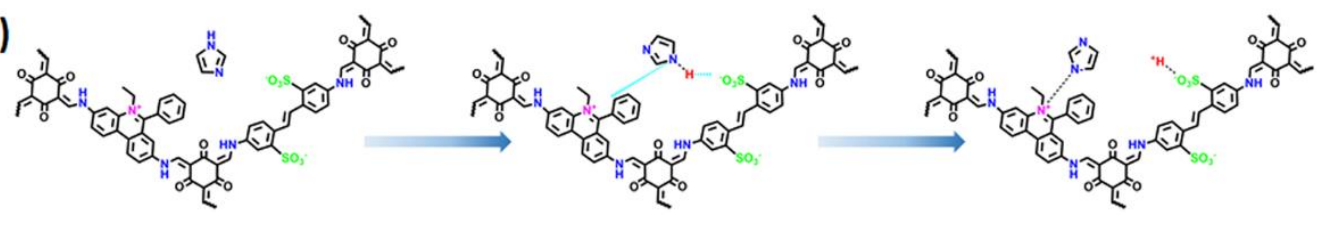

Figure S53. Graphic representations of proton dissociation energy values for (a)trz@XJCOF-3 and (b)im@XJCOF-3. 
(a)

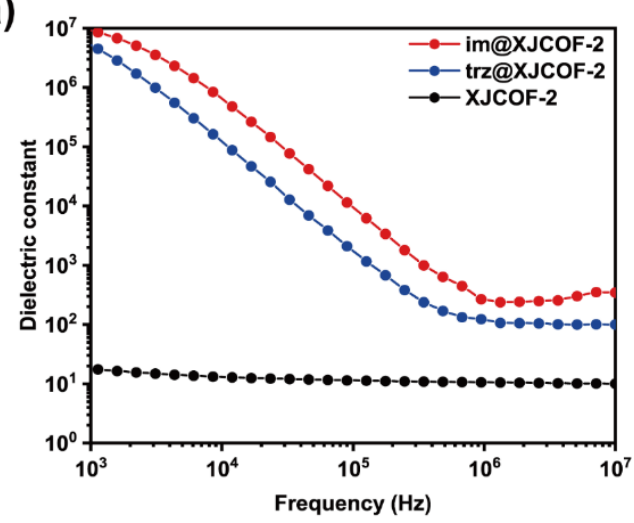

(b)

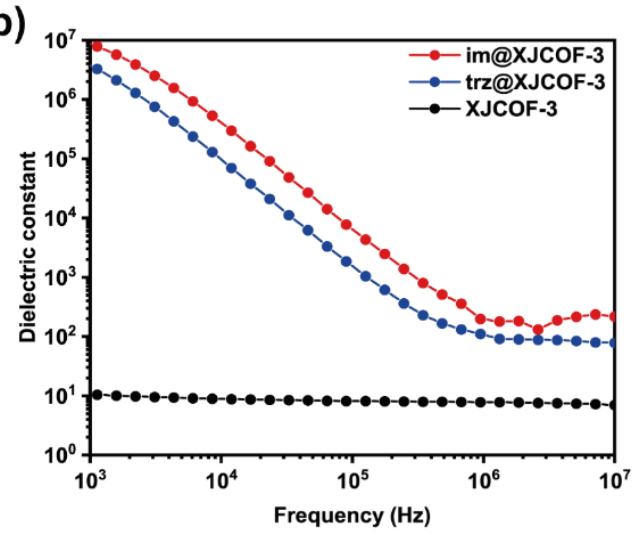

Figure S54. Dielectric constant of (a)XJCOF-2 and (b)XJCOF-3 before and after doping triazole and imidazole.

(a)

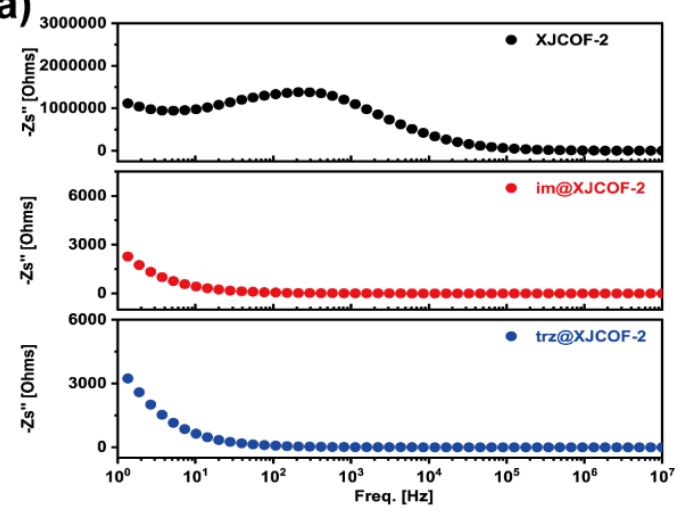

(b)

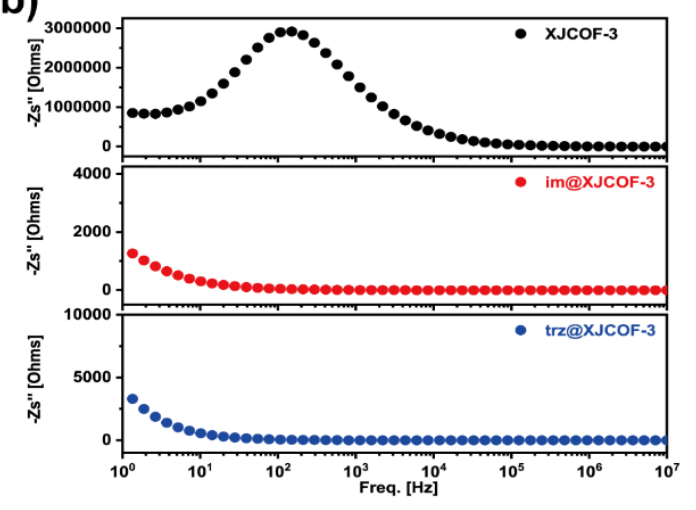

Figure S55. Debye plots of imaginary impedance of (a)XJCOF-2 and (b)XJCOF-3 as a function of frequency. 


\section{References:}

(1) Savage, M.; Cheng, Y.; Easun, T. L.; Eyley, J. E.; Argent, S. P.; Warren, M. R.; Lewis, W.; Murray, C.; Tang, C. C.; Frogley, M. D.; Cinque, G.; Sun, J.; Rudić, S.; Murden, R. T.; Benham, M. J.; Fitch, A. N.; Blake, A. J.; Ramirez-Cuesta, A. J.; Yang, S.; Schröder, M. Selective Adsorption of Sulfur Dioxide in a Robust Metal-Organic Framework Material. Adv. Mater. 2016, 28, 8705-8711.

(2) Cui, X.; Yang, Q.; Yang, L.; Krishna, R.; Zhang, Z.; Bao, Z.; Wu, H.; Ren, Q.; Zhou, W.; Chen, B.; Xing, H. Ultrahigh and Selective $\mathrm{SO}_{2}$ Uptake in Inorganic Anion-Pillared Hybrid Porous Materials. Adv. Mater 2017, 29, 1606929.

(3) Carter, J. H.; Han, X.; Moreau, F. Y.; da Silva, I.; Nevin, A.; Godfrey, H. G. W.; Tang, C. C.; Yang, S.; Schröder, M. Exceptional Adsorption and Binding of Sulfur Dioxide in a Robust Zirconium-Based Metal-Organic Framework. J. Am. Chem. Soc. 2018, 140, 1556415567.

(4) Yang, S.; Sun, J.; Ramirez-Cuesta, A. J.; Callear, S. K.; David, W. I. F.; Anderson, D. P.; Newby, R.; Blake, A. J.; Parker, J. E.; Tang, C. C.; Schröder, M. Selectivity and Direct Visualization of Carbon Dioxide and Sulfur Dioxide in a Decorated Porous Host. Nat. Chem. 2012, 4, 887-894.

(5) Zárate, J. A.; Sánchez-González, E.; Williams, D. R.; González-Zamora, E.; Martis, V.; Martínez, A.; Balmaseda, J.; Maurin, G.; Ibarra, I. A. High and Energy-Efficient Reversible $\mathrm{SO}_{2}$ Uptake by a Robust Sc(iii)-Based MOF. J. Mater. Chem. A 2019, 7, 1558015584.

(6) Chen, Z.; Wang, X.; Cao, R.; Idrees, K. B.; Liu, X.; Wasson, M. C.; Farha, O. K. Water-Based Synthesis of a Stable Iron-Based Metal-Organic Framework for Capturing Toxic Gases. ACS Mater. Lett. 2020, 2, 1129-1134.

(7) Smith, G. L.; Eyley, J. E.; Han, X.; Zhang, X.; Li, J.; Jacques, N. M.; Godfrey, H. G. W.; Argent, S. P.; McCormick McPherson, L. J.; Teat, S. J.; Cheng, Y.; Frogley, M. D.; Cinque, G.; Day, S. J.; Tang, C. C.; Easun, T. L.; Rudić, S.; Ramirez-Cuesta, A. J.; Yang, S.; Schröder, M. Reversible Coordinative Binding and Separation of Sulfur Dioxide in a Robust Metal-Organic Framework with Open Copper Sites. Nat. Mater. 2019, 18, 13581365.

(8) Fan, Y. L.; Zhang, H. P.; Yin, M. J.; Krishna, R.; Feng, X. F.; Wang, L.; Luo, M. B.; Luo, F. High Adsorption Capacity and Selectivity of $\mathrm{SO}_{2}$ over $\mathrm{CO}_{2}$ in a Metal-Organic Framework. Inorg. Chem. 2021, 60, 4-8.

(9) Yang, S.; Liu, L.; Sun, J.; Thomas, K. M.; Davies, A. J.; George, M. W.; Blake, A. J.; Hill, A. H.; Fitch, A. N.; Tang, C. C.; Schröder, M. Irreversible Network Transformation in a Dynamic Porous Host Catalyzed by Sulfur Dioxide. J. Am. Chem. Soc. 2013, 135, 49544957.

(10) Tan, K.; Canepa, P.; Gong, Q.; Liu, J.; Johnson, D. H.; Dyevoich, A.; Thallapally, P. K.; Thonhauser, T.; Li, J.; Chabal, Y. J. Mechanism of Preferential Adsorption of $\mathrm{SO}_{2}$ into Two Microporous Paddle Wheel Frameworks $\mathrm{M}(\mathrm{bdc})(\mathrm{ted})_{0.5}$. Chem. Mater. 2013, 25, 
4653-4662.

(11) Li, L.; da Silva, I.; Kolokolov, D. I.; Han, X.; Li, J.; Smith, G.; Cheng, Y.; Daemen, L. L.; Morris, C. G.; Godfrey, H. G. W.; Jacques, N. M.; Zhang, X.; Manuel, P.; Frogley, M. D.; Murray, C. A.; Ramirez-Cuesta, A. J.; Cinque, G.; Tang, C. C.; Stepanov, A. G.; Yang, S.; et al. Post-Synthetic Modulation of the Charge Distribution in a Metal-Organic Framework for Optimal Binding of Carbon Dioxide and Sulfur Dioxide. Chem. Sci. 2019, $10,1472-1482$.

(12) Fu, Y.; Wang, Z.; Li, S.; He, X.; Pan, C.; Yan, J.; Yu, G., Functionalized Covalent Triazine Frameworks for Effective $\mathrm{CO}_{2}$ and $\mathrm{SO}_{2}$ Removal. ACS Appl. Mater. Interfaces 2018, 10, 36002-36009.

(13) Ashraf, S.; Liu, C.; Li, S.; Haq, I.-u.; Mehmood, M.; Li, P.; Wang, B., Versatile Platform of Ion Conducting 2D Anionic Germanate Covalent Organic Frameworks with Potential for Capturing Toxic Acidic Gases. ACS Appl. Mater. Interfaces 2020, 12, 4037240380.

(14) Lee, G.-Y.; Lee, J.; Vo, H. T.; Kim, S.; Lee, H.; Park, T., Amine-Functionalized Covalent Organic Framework for Efficient $\mathrm{SO}_{2}$ Capture with High Reversibility. Sci. Rep. 2017, 7, 557.

(15) Suo, X.; Yu, Y.; Qian, S.; Zhou, L.; Cui, X.; Xing, H., Tailoring the Pore Size and Chemistry of Ionic Ultramicroporous Polymers for Trace Sulfur Dioxide Capture with High Capacity and Selectivity. Angew. Chem., Int. Ed. 2021, 60, 6986-6991.

(16) Zhang, J.-Y.; Zhang, J.-B.; Li, M.; Wu, Z.; Dai, S.; Huang, K., Solvent-Free and One-Pot Synthesis of Ultramicroporous Carbons with Ultrahigh Nitrogen Contents for Sulfur Dioxide Capture. Chem. Eng. J. 2020, 391, 123579.

(17) Martínez-Ahumada, E.; He, D.; Berryman, V.; López-Olvera, A.; Hernandez, M.; Jancik, V.; Martis, V.; Vera, M. A.; Lima, E.; Parker, D. J.; Cooper, A. I.; Ibarra, I. A.; Liu, M., $\mathrm{SO}_{2}$ Capture Using Porous Organic Cages. Angew. Chem., Int. Ed. 2021, 60, 1755617563.

(18) An, X.-C.; Li, Z.-M.; Zhou, Y.; Zhu, W.; Tao, D.-J., Rapid Capture and Efficient Removal of Low-Concentration $\mathrm{SO}_{2}$ in Simulated Flue Gas by Hypercrosslinked Hollow Nanotube Ionic Polymers. Chem. Eng. J. 2020, 394, 124859.

(19) Chen, S.; Wu, Y.; Zhang, Y.; Zhang, W.; Fu, Y.; Huang, W.; Yan, T.; Ma, H. Tuning Proton Dissociation Energy in Proton Carrier Doped 2D Covalent Organic Frameworks for Anhydrous Proton Conduction at Elevated Temperature. J. Mater. Chem. A 2020, 8, 1370213709.

(20) Xu, H.; Tao, S.; Jiang, D. Proton Conduction in Crystalline and Porous Covalent Organic Frameworks. Nat. Mater. 2016, 15, 722-726.

(21) Ye, Y.; Zhang, L.; Peng, Q.; Wang, G. E.; Shen, Y.; Li, Z.; Wang, L.; Ma, X.; Chen, Q. H.; Zhang, Z.; Xiang, S. High Anhydrous Proton Conductivity of Imidazole-Loaded Mesoporous Polyimides over a Wide Range from Subzero to Moderate Temperature. J. Am. Chem. Soc. 2015, 137, 913-918.

(22) Li, S.; Liu, Y.; Li, L.; Liu, C.; Li, J.; Ashraf, S.; Li, P.; Wang, B. Enhanced Proton 
Conductivity of Imidazole-Doped Thiophene-Based Covalent Organic Frameworks via Subtle Hydrogen Bonding Modulation. ACS Appl. Mater. Interfaces 2020, 12, 2291022916.

(23) Bureekaew, S.; Horike, S.; Higuchi, M.; Mizuno, M.; Kawamura, T.; Tanaka, D.; Yanai, N.; Kitagawa, S. One-Dimensional Imidazole Aggregate in Aluminium Porous Coordination Polymers with High Proton Conductivity. Nat. Mater. 2009, 8, 831-836.

(24) Umeyama, D.; Horike, S.; Inukai, M.; Itakura, T.; Kitagawa, S. Inherent Proton Conduction in a 2D Coordination Framework. J. Am. Chem. Soc. 2012, 134, 12780-12785.

(25) Hurd, J. A.; Vaidhyanathan, R.; Thangadurai, V.; Ratcliffe, C. I.; Moudrakovski, I. L.; Shimizu, G. K. H. Anhydrous Proton Conduction at $150{ }^{\circ} \mathrm{C}$ in a Crystalline MetalOrganic Framework. Nat. Chem. 2009, 1, 705-710.

(26) Cao, J.; Ma, W.; Lyu, K.; Zhuang, L.; Cong, H.; Deng, H. Twist and Sliding Dynamics between Interpenetrated Frames in Ti-MOF Revealing High Proton Conductivity. Chem. Sci. 2020, 11, 3978-3985.

(27) Liu, S.; Yue, Z.; Liu, Y. Incorporation of Imidazole within the Metal-Organic Framework UiO-67 for Enhanced Anhydrous Proton Conductivity. Dalton Trans. 2015, 44, 12976-12980.

(28) Homburg, T.; Hartwig, C.; Reinsch, H.; Wark, M.; Stock, N. Structure Property Relationships Affecting the Proton Conductivity in Imidazole Loaded Al-MOFs. Dalton Trans. 2016, 45, 15041-15047.

(29) Tao, S.; Zhai, L.; Dinga Wonanke, A. D.; Addicoat, M. A.; Jiang, Q.; Jiang, D. Confining $\mathrm{H}_{3} \mathrm{PO}_{4}$ Network in Covalent Organic Frameworks Enables Proton Super Flow. Nat. Commun. 2020, 11, 1981.

(30) Wu, X.; Hong, Y. L.; Xu, B.; Nishiyama, Y.; Jiang, W.; Zhu, J.; Zhang, G.; Kitagawa, S.; Horike, S. Perfluoroalkyl-Functionalized Covalent Organic Frameworks with Superhydrophobicity for Anhydrous Proton Conduction. J. Am. Chem. Soc. 2020, 142, 14357-14364.

(31) Huang, W.; Li, B.; Wu, Y.; Zhang, Y.; Zhang, W.; Chen, S.; Fu, Y.; Yan, T.; Ma, H. In Situ-Doped Superacid in the Covalent Triazine Framework Membrane for Anhydrous Proton Conduction in a Wide Temperature Range from Subzero to Elevated Temperature. ACS Appl. Mater. Interfaces 2021, 13, 13604-13612.

(32) Chandra, S.; Kundu, T.; Dey, K.; Addicoat, M.; Heine, T.; Banerjee, R. Interplaying Intrinsic and Extrinsic Proton Conductivities in Covalent Organic Frameworks. Chem. Mater. 2016, 28, 1489-1494.

(33) Shinde, D. B.; Aiyappa, H. B.; Bhadra, M.; Biswal, B. P.; Wadge, P.; Kandambeth, S.; Garai, B.; Kundu, T.; Kurungot, S.; Banerjee, R. A Mechanochemically Synthesized Covalent Organic Framework as a Proton-Conducting Solid Electrolyte. J. Mater. Chem. A 2016, 4, 2682-2690.

(34) Chandra, S.; Kundu, T.; Kandambeth, S.; BabaRao, R.; Marathe, Y.; Kunjir, S. M.; Banerjee, R. Phosphoric Acid Loaded Azo $(-\mathrm{N}=\mathrm{N}-)$ Based Covalent Organic Framework for Proton Conduction. J. Am. Chem. Soc. 2014, 136, 6570-6573. 